\title{
Molecular imaging with nanoparticles: giant roles for dwarf actors
}

\author{
Paul Debbage $\cdot$ Werner Jaschke
}

Accepted: 5 September 2008 / Published online: 30 September 2008

(C) Springer-Verlag 2008

\begin{abstract}
Molecular imaging, first developed to localise antigens in light microscopy, now encompasses all imaging modalities including those used in clinical care: optical imaging, nuclear medical imaging, ultrasound imaging, CT, MRI, and photoacoustic imaging. Molecular imaging always requires accumulation of contrast agent in the target site, often achieved most efficiently by steering nanoparticles containing contrast agent into the target. This entails accessing target molecules hidden behind tissue barriers, necessitating the use of targeting groups. For imaging modalities with low sensitivity, nanoparticles bearing multiple contrast groups provide signal amplification. The same nanoparticles can in principle deliver both contrast medium and drug, allowing monitoring of biodistribution and therapeutic activity simultaneously (theranostics). Nanoparticles with multiple bioadhesive sites for target recognition and binding will be larger than $20 \mathrm{~nm}$ diameter. They share functionalities with many subcellular organelles (ribosomes, proteasomes, ion channels, and transport vesicles) and are of similar sizes. The materials used to synthesise nanoparticles include natural proteins and polymers, artificial polymers, dendrimers, fullerenes and other carbon-based structures, lipid-water micelles, viral capsids, metals, metal oxides, and ceramics. Signal generators incorporated into nanoparticles include iron oxide, gadolinium, fluorine, iodine, bismuth, radionuclides, quantum dots,
\end{abstract}

\section{P. Debbage $(\square)$}

Department of Anatomy, Division of Histology and Embryology, Medical University Innsbruck, Muellerstrasse 59,

6020 Innsbruck, Austria

e-mail: Paul.Debbage@i-med.ac.at

W. Jaschke

Department of Radiology, Innsbruck Medical University, Anichstrasse 35, 6020 Innsbruck, Austria and metal nanoclusters. Diagnostic imaging applications, now appearing, include sentinal node localisation and stem cell tracking.

Keywords Molecular imaging · Nanoparticles · Nanomedicine $\cdot$ Targeting $\cdot$ Theranostics

\section{Introduction}

The introduction of laser illumination, scanning imaging, digital detectors, computerisation, and time gating into light microscopy in recent years has opened new vistas in analysis of intracellular mechanics and tissue biology. Further advances in resolution promise yet deeper insights as new types of microscope evade the classical diffraction limits of spatial resolution (Szellas and Hoppe 2007). However, at the same time as light microscopical imaging is breaking new ground, a new field of research has emerged, namely molecular imaging. This encompasses advances in several non-microscopical imaging modalities, some of which are of first-order clinical importance. The availability of new hardware, together with advances in computer-supported image processing, has facilitated advances in these forms of imaging, just as in microscopy. The over-arching new field of molecular imaging unites all the disparate imaging modalities, including light microscopy, into a single research area with shared aims and technical challenges. The endeavour to visualise particular molecules within a tissue can be traced back to the work of histologists such as Feulgen (Benedum and Meusch 1999) developing specific reagents for DNA, proteins (eosin), and carbohydrates (PAS). Early workers used inorganic reagents and organic dyes, many of them still in common use (Mulisch and Welsch 2008). The birth of molecular imaging dates to Coon's use 
of the exquisite specificity of antibodies as immune reagents, applying a targeting group (an antibody) to steer a signal emitter (a fluorochrome) into targets in tissues for fluorescence microscopy (Coons 1961). Today, the targeting group may be any of a range of molecules, including antibodies and antibody fragments, nucleotides, and specific ligands, and the signal emitter can consist of a wide range of materials according to the particular imaging modality being applied, including organic fluorochromes, metals, metal oxides, and bubbles. The imaging systems now include direct optical imaging using several regions of the optical spectrum, and also indirect imaging in which scanning systems are coupled with computerised calculation to derive images, including non-orthogonal and threedimensional images. Photons, ultrasound, and magnetic fields all are used to obtain images, which allow for analysis of molecular interaction, for example, receptor binding, or tissue tagging, for example, in malignant disease. Underlying this colourful variety of imaging systems and new applications, there is a core of common technical considerations, and of challenges to be solved. To overcome a challenge in one type of imaging means an advance in the whole field of molecular imaging, and technical solutions developed in one imaging modality can be modified slightly and applied to other types of imaging with relative ease. It has become evident during recent years that several of the challenges facing molecular imaging can be overcome by use of nanostructured materials, and nanoparticles now feature in all areas of molecular imaging. Molecular imaging resembles the elephant in the Indian story, difficult to experience in its entirety and therefore reported by different authors in quite different ways. To underscore the unity of the field, we will therefore consider first the various imaging modalities, noting their common aspects but also their particular characteristics. For the histologist, many of the technical parameters are familiar in daily experience, though in some imaging modalities they have quite unexpected values. Other parameters are present in light microscopy though rarely considered, yet stand in the forefront of other imaging technologies. Before turning to consider nanoparticles, we will review briefly the various types of imaging modality now in common (usually clinical) use or presently undergoing development.

\section{Light microscopy}

Molecular Imaging is familiar to the histologist in the form of immunohistochemistry and of in situ hybridisation, which visualise certain specific types of molecule, but not others, in the microscope. Even classical histochemical stains achieve this; possibly, the most familiar form of molecular imaging is haematoxylin and eosin (H\&E), which generates images distinguishing two major molecule types. Some features of H\&E in light microscopy represent advanced molecular imaging in that it provides direct multicolour imaging of two classes of molecule simultaneously by use of a single illumination source, with immediate visualisation by eye. For these reasons amongst others, it is the mainstay of clinical histopathology and the source of most differential diagnoses guiding choice between therapeutic options. It is therefore of prime clinical importance, and sets standards for other imaging modalities. Light microscopy offers much more, however. Following the introduction of antibodies as reagents by Coons, immunohistochemistry was enriched by introduction of indirect labelling, availability of monoclonal antibodies, enzyme tracers, confocal scanning laser microscopy, twophoton microscopy, and others. In the near future, antibody fragments, generated both with and without the use of animal immunization, will further enhance this technique. Immunospecific labelling has been complemented by nucleotide-specific labelling in the form of in situ hybridisation to reveal genetic sequences in tissues. The genetic modification of certain proteins to allow them to be traced in cells that express them represents a further form of light microscopical molecular imaging. This area of work in histochemistry is presently active and productive, as seen in the continued development of new stains and methods for visualising and evaluating them, often by close interaction with quite different disciplines, for example, the genetic introduction of contrast groups into living animals (Lanman et al. 2008; Livet et al. 2007). It has become possible to view specific molecule types in living cells at high spatial and temporal resolution (sub-micrometre, milliseconds), and to track them for days, without significant damage to the cells. Accurate imaging of molecule types in tissue sections as thick as $50 \mu \mathrm{m}$ is possible, with sub-micrometre resolutions. As required, light microscopical molecular imaging can be complemented by electron microscopical molecular imaging, which visualises multiple molecule types simultaneously in single sections at better than $10 \mathrm{~nm}$ resolution (Roth 1983).

Light microscopy offers ideal conditions for molecular imaging: in classical histology, the stain is applied to fixed, delipidated, and sectioned materials in which all structures are cut through and sites to be contrasted lie open to the stain. Light microscopy leads the molecular imaging field in several respects, but it has a major limitation: the short focal lengths of the microscope objectives prohibit use on living subjects larger than about $1 \mathrm{~mm}$ in size. Also, unlike the imaging modalities in clinical use, it tolerates the use of toxic contrast agents and does not need to consider issues related to pharmacokinetics.

Antibodies are not the only nanoparticles in use in light and electron microscopy. Quantum dots have introduced entirely new fields of investigation, which could not be 
undertaken earlier because organic fluorochromes faded and bleached, and had insufficient quantum yields. Organic fluorochromes can be detected at approximately levels down to $10^{-8}$ moles.

\section{Optical imaging}

The near-infrared part of the optical spectrum is exploited in light microscopy by use of fluorochromes emitting at wavelengths up to about $700 \mathrm{~nm}$. Microscope lenses are not designed for use at much higher wavelengths than this. However, camera lenses can be used throughout the nearinfrared spectrum, 600-900 nm, and this opens the imaging modality known simply as "optical imaging" (see Fig. 1a). The infrastructure required is particularly inexpensive: a normal digital camera and a source of filtered infrared light are sufficient to produce good-quality images. The nearinfrared wavelengths between 600 and $900 \mathrm{~nm}$ provide a near-transparency of living tissue. The cytochromes and other pigments within the living cells cease to absorb at wavelengths near and above $600 \mathrm{~nm}$, and water molecules only begin to absorb near and above $900 \mathrm{~nm}$. However, the transparency is not complete, and penetration of near-infrared light into the body is limited to a few centimetres. Higher intensities above approximately $1,200 \mathrm{~W} / \mathrm{cm}^{2}$ overheat the tissues, preventing deeper penetration by raising the intensity of the light used. Thus, for clinical work, the penetration depth limits the applicability of optical molecular imaging. This is much to be regretted because this image modality is patient-friendly. It is finding clinical use in localisation of sentinel nodes in large animals and potentially in cancer patients, using picomolar amounts of quantum dots and low light intensities, $5 \mathrm{~mW} / \mathrm{cm}^{2}$ (Kim et al. 2003). For biomedical research, the case is quite different, because in animals smaller than rabbits, the opacity of their tissues to visible wavelengths does not prevent penetration of some light to the centre of the animal. Irradiation of the animals with blue light is therefore adequate to visualise green-fluorescing proteins within the animal's internal organs. Therefore, in mice, optical imaging is a popular approach to study gene expression, protein expression, for example GFP, and localisation of tumours by use of fluorescent-labelled antibodies. This renders the use of animal models as test beds in optical imaging a useful means of developing nanoparticles for use in other imaging modalities. A varied collection of fluorochromes has been used, including quantum dots (Bruchez et al. 1998; Chan and Nie 1998; Alivisatos 2004), organic fluorochromes, and colloidal metals.

\section{Photoacoustic imaging}

Photoacoustic imaging, sometimes also called optoacoustic or thermoacoustic imaging, is a promising novel imaging modality for non-invasive visualisation of semitransparent objects, including soft biological tissue and biological samples (see Fig. 1b). It combines the advantages of optical and ultrasound modalities. The principle of photoacoustics is as follows. When short pulses of electromagnetic radiation, such as light or radio waves, illuminate a semitransparent object, a sound wave is induced at the point of interest deep inside the sample via the thermoelastic effect. In photoacoustic imaging, the goal is to recover the spatially varying distribution of the absorbed energy inside the illuminated sample from the acoustic pressure measured outside the sample. Structures of different biological tissues reveal highly varying optical absorption coefficients, and thus, photoacoustic imaging provides a good distinction between malignant and healthy tissue, for example. Moreover, it is expected to be useful in the early detection of cancer and blood-rich lesions in vivo. It is also expected to provide high resolution in microscopy. There are two major areas of non-invasive in vitro and in vivo photoacoustic imaging, the first of which, "photoacoustic imaging", applies unfocused ultrasound. In real-time free hand photoacoustic imaging, a part of the sample is visualised (Niederhauser 2004) and image reconstruction methods are necessary to obtain the spatial information out of the measured data. In full "photoacoustic tomography (PAT)", either a complete slice or the whole volume of the sample is reconstructed (Kruger et al. 2002; Wang et al. 2003). In the literature, several different approaches to PAT imaging have been proposed [see (Xu and Wang 2006) for an up-to-date survey on existing methods]. Current imaging systems provide spatial resolution in the range of $100 \mu \mathrm{m}$, and this is expected to improve further in the future. The second technique is "photoacoustic microscopy (PAM)" (Zhang et al. 2006), which scans a focused ultrasound transducer along the sample surface, and converts each received timeresolved signal into a one-dimensional image along the acoustic axis of the transducer; combining multiple images acquired sequentially from various positions then produces cross-sectional or three-dimensional images without use of a reconstruction method as required in tomography. Driven by potential medical applications, the area of photoacoustics is growing rapidly and steadily. Recently, there has been considerable effort to establish PAT as a tool in preclinical research. Various groups have built small animal imagers and have achieved promising results, for instance imaging of the vasculature in the brain (Wang et al. 2003; Kruger et al. 2003), and promising animal studies (Wang et al. 2003, 2006; Zhang et al. 2006), and methods for obtaining accurate, spatially resolved values of blood oxygenation (Laufer et al. 2005; Wang et al. 2006; Zhang et al. 2006). High-resolution photoacoustic imaging is ideally useful for screening of biological samples in the range of millimetres up to some centimetres, which makes it ideally 


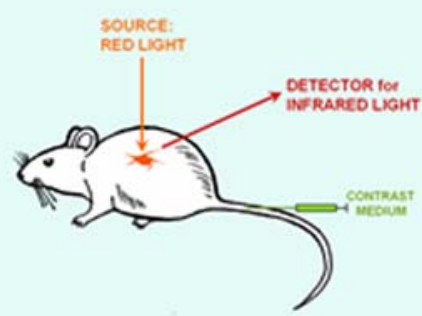

A

OPTICAL IMAGING

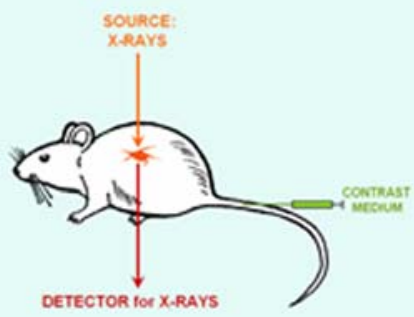

C

$X$-RAY IMAGING

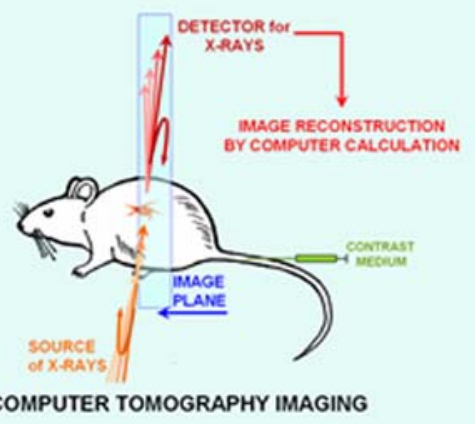

E

suited to gain complementary information in small animal imaging. PAT imaging has also been used in connection with high-intensity focused ultrasound to monitor tumour treatment processes (Jin et al. 2005). Finally, photoacoustic tomography complements existing imaging methods, and fusion with CT, MRI, or ultrasound can provide significant additional diagnostic information (Niederhauser 2004).

\section{X-ray imaging}

Visualisation of the internal organs in living creatures first became a possibility in 1895, when Röntgen discovered X-rays (Elke 1995). His first image demonstrated the principle of differential contrast available between bone, soft tissues, and air-filled structures using radiography, and this principle is followed until today (Seibert and Boone 2005). Placing the animal between the X-ray source (about $30 \mathrm{kV}$ ) and a detector casts a projected image onto the detector (see Fig. 1c). This type of image has an inherent high spatial

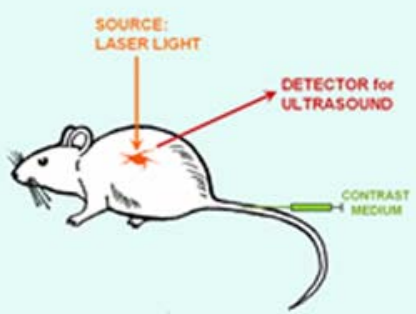

B
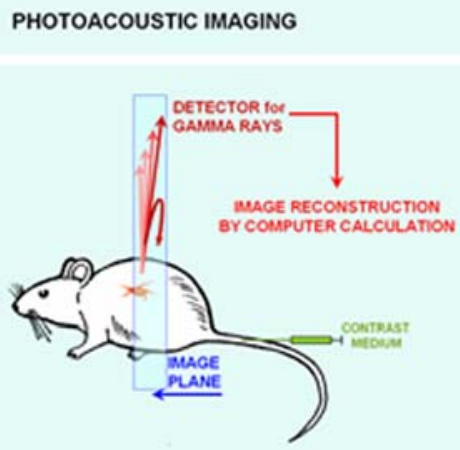

PET IMAGING

D

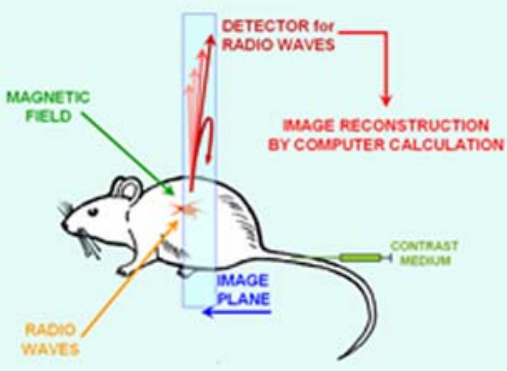

MAGNETIC RESONANCE IMAGING

$\mathbf{F}$

resolution for high-contrast objects, but suffers from poor contrast resolution. In principal, X-rays have the potential to visualise subatomic structures, but the effective resolution in vivo is limited by the hardware, object size, and object geometry. Nonetheless, by use of flatpanel detectors or high-resolution films and microfocus tubes, the objects resolved are as small as $10 \mu \mathrm{m}$, which is the highest resolution presently available for in vivo imaging of internal organs of living animals. The infrastructure can be relatively simple and inexpensive, and provides direct imaging (no calculation is required). The monochrome images can be viewed immediately on a monitor, with rapid adjustment of image contrast and magnification. Contrast is generated by absorption of the X-rays in the living tissues, and this absorption is more effective, the higher the atomic number (n) of the absorptive elements involved. Usually calcium (atomic number $n=20$ ) in bones provides the contrast, though barium (GI tract) and iodine compounds (i.v. administration) are used ( $n=56$ and 53, respectively), and 
Fig. 1 Sketches illustrating the basic function of each imaging modality. In each case, the subject is a mouse bearing a tumour in one of its internal organs. a Optical imaging: the sketch shows a configuration, which maximises optical penetration into tissues, with red light (e.g., from a light-emitting diode) causing fluorescence of a targeted fluorochrome in the disease site, with detection of the fluorescence by, for example, a camera. This is the only imaging modality shown here, which employs a lens to focus the image; the combination of monochromatic light for excitation, and lens, filter, and camera to capture the image, renders this imaging modality familiar to microscopists. For small animals as shown here, the blue and green parts of the visible spectrum can be employed instead of the red and near-infrared, but for subjects larger than rabbits the red/near-infrared is necessary to provide better tissue penetration. The configuration shown here generates a projected image; by use of multi-angle exposures and scanning, followed by reconstructive calculation, optical imaging can be used to obtain three-dimensional images, but this is not essential in this imaging modality. Optical imaging can detect targeted fluorochromes injected into the bloodstream (e.g., fluorochrome-tagged immunoliposomes), but can also detect cells, which have been genetically engineered to express fluorescent proteins, in which case no injection is required just prior to imaging. b Photoacoustic imaging: the configuration shown in this sketch uses one axis for illumination and a separate axis for detection of the ultrasound signal. Configurations with a single axis for both illumination and also for ultrasound detection have been described. The sketch omits the multi-angle multiple acquisition, the scanning procedure, and the image reconstructive calculation that are necessary (compare CT imaging below), to emphasise the basic principle of this new imaging modality. Photoacoustic imaging does not always require injection of a contrast medium, because haemoglobin generates strong signals, allowing "native" imaging of blood vessels. If contrast in a lesion is required, this can be obtained by injection of targeted nanoparticles. c X-ray imaging: conceptually, this is the simplest imaging modality shown here. An X-ray beam illuminates the subject and dense structures within the tissue cast shadows onto a detector (film or a solid-state detector), to form an image. The disease site in soft tissues will not be visible in the image unless X-ray-dense materials have been introduced into the lesion. Injection of a contrast medium, for example, targeted metal nanoparticles, is therefore essential for acquisition of contrast images. This modality has extremely high spatial resolution, is readily available in the form of small machines in physicians' offices, and is cheap to instal and simple to use. Images are available for viewing a few seconds after acquisition, which itself requires less than $1 \mathrm{~s}$.

contrast can also be introduced by introduction of air (atomic numbers of nitrogen and oxygen are 8 and 7 , respectively, and the specific density of air is much lower than that of the aqueous surrounding living tissues). The metals used in dentistry (20-35\% silver, with $n=47$; tin, with $n=50 ; \sim 10 \%$ copper, with $n=29 ; \sim 2 \%$ zinc, with $n=30 ; 43-54 \%$ mercury, with $n=80$ ) provide much higher contrast. Molecular imaging by use of gold nanoparticles (atomic number $=79$ ) to generate localised contrast in X-ray-projected images would therefore seem to be a promising approach. This imaging modality exposes the living subject to ionising radiation, which has additive effects and therefore can be applied as a diagnostic tool to the same subject only until a certain safe dose has been reached. However, diagnostic imaging operates at a dose level, where radiation injuries are not encountered, even if large numbers of exposures are taken.
The image obtained is a direct projection-there is no reconstructive calculation - and is therefore free of many types of artefact. d PET imaging: amongst the imaging modalities shown here, this is the only one, which requires no external "illumination" to generate an image. The radionuclides are injected as "contrast agent" approximately $1 \mathrm{~h}$ prior to imaging, and accumulate in the target. From this location, they emit gamma rays, which are detected by specialised detectors. Multiangle multiple acquisitions in each image plane are necessary, indicated in the sketch by arrows circling in the image plane. Multiple image planes must be acquired by successive scanning of image planes along the axis of the subject, as indicated in the illustration; the data is processed by reconstructive calculation in a computer to generate images. To aid illustration, the image plane in the sketch is shown much thicker than it actually is during real-life imaging. e CT imaging: this version of X-ray imaging functions exactly as described above, but with the addition of multi-angle multiple image acquisitions in the image plane, indicated in the sketch by arrows circling in the image plane. Data from multiple image planes must be acquired by scanning along the axis of the subject, as indicated in the illustration, and complex reconstructive calculations are then carried out by computer to generate images in any desired plane through the subject, or to generate three-dimensional images. The engineering required for this type of image acquisition renders the equipment large, complex, and costly. Acquisition of images requires many minutes; the radiation dose is much higher than in direct X-ray imaging. However, this is the only imaging modality, which can locate lesions in a human subject at much better than sub-millimetre accuracy, and in three dimensions. f MR imaging: the two external sources required for imaging, namely strong magnetic fields and high-frequency radio waves, are depicted here, ignoring details of the geometric relationships. The signals emitted from the subject are also in the form of radio waves, and are detected by receive coils positioned around the subject. Multi-angle multiple acquisitions are required in each imaging plane, as indicated in the sketch by arrows circling in the image plane. Data from multiple image planes are acquired by scanning along the axis of the subject, and the data is processed by reconstructive calculation in a computer to generate images in any desired plane through the subject, or three-dimensional images. Soft tissues are imaged with good contrast; so, injection of a contrast medium is not always required. However, specific highcontrast imaging of specific molecules requires injection of targeted materials containing either iron oxides or a contrast agent such as gadolinium. As for CT and PET imaging, image acquisition times may be major fractions of $1 \mathrm{~h}$

\section{PET/SPECT imaging}

The possibilities of molecular imaging multiplied manyfold with the advent of strongly emitting radioisotopes, giving birth to nuclear medicine between 1930 and 1950 (Feld and De Roo 2003). The imaging modality is positron emission tomography (PET), using high-energy gamma rays generated in a chain of nuclear radioactive reactions involving production of positrons. The gamma rays have subatomic resolution, though the effective spatial resolution is limited by the detector hardware and geometry to about $1 \mathrm{~mm}$. In PET, there is no external source of illumination (see Fig. 1d). The radioactive tracer is injected into the living subject and positrons are produced at the site of the disease lesion, and their annihilation with electrons produces gamma rays at that site; the subject is illuminated from within the tissues. The gamma rays emitted from the disease 
site(s) are detected by detectors arranged close to and partly surrounding the subject. As in CT, the various strengths and origin of signal detected within the detector array are calculated by a computer to reconstruct the signal intensity at each point in the common plane, and presented as a monochrome image of that plane. By scanning along the living subject, a series of image planes is reconstructed and further calculation allows reconstruction of the image in any desired plane through the subject. PET requires no signal amplification, because the gamma rays have energies in the megavolt range; regarding contrast resolution, i.e., efficiency to detect minute concentrations of radionuclides in tissue, PET is the most sensitive of all the imaging modalities: the radionuclides deposited in the living subject can be detected at amounts as low as $10^{-11}$ moles, allowing as few as a single cell to be detected by binding only two to three labelled antibody molecules, e.g., somatostatin receptors in neuro-endocrine tumours (de Herder et al. 2005). Because of spatial resolution limitations, however, these miniscule amounts of tracer cannot be localised within the living subject to closer than approximately $2 \mathrm{~mm}$. Thus, PET suffers from a rather poor anatomical resolution. This is overcome by hybrid imaging, in which PET is used to track molecular events and high-resolution CT for localising the events. Thanks to the extremely high sensitivity of PET, the use of antibody molecules with single radionuclide atoms attached is common. However, for multiple targeting, nanoparticles are being considered. This branch of medicine already reaches "theranostics", the combination of diagnosis and therapy in a single structure (Boisseau et al. 2006). PET however exposes the living tissue to strongly ionising radiation, and due to the pharmacokinetics, there is always a high radiation dose to the kidneys. This is an extremely expensive imaging modality and requires an extensive infrastructure. The imaging centre either requires a nearby cyclotron to generate the positron-emitting radionuclides, or it must have a reliable connection with a more distant source-possibly a few hundred kilometres distantwith excellent logistics to deliver the radionuclides to the imaging centre with a time interval not longer than a few halflives. A radiochemical laboratory to handle the highly radioactive isotopes is also an essential part of the infrastructure.

\section{Computed tomography X-ray imaging}

Although computed tomography X-ray imaging (CT) employs X-rays for generating an image, this is a very different form of imaging from direct $\mathrm{X}$-ray projection imaging (see Fig. 1e). During image acquisition, the X-ray tube rotates around the object. Transmission profiles are sampled from up to 360 angles in digitized form using solid-state detectors. Data is processed by dedicated computer hardware using reconstruction algorithms to reconstruct the optical densities at each point in the common imaging plane. This reconstruction is presented as a cross-sectional image providing superb contrast resolution and adequate spatial resolution. Volume scanning is achieved by moving the subject continuously through the scanning beam; the volume data set allows reconstruction of any desired plane through the subject. The possibilities of acquiring contrasted molecular images are the same as in direct projection X-ray imaging. In $\mathrm{CT}$, however, contrast molecules can be pinpointed in three dimensions to millimetre accuracy. In addition, dual energy imaging at different kilovolt-settings allows high precision quantification of contrast materials, calcium and other radioopaque materials, as well as fat, for example, in fatty tissue or the liver. Also, bone subtraction for demonstration of blood vessels can easily be obtained. Dedicated animal/small objects-imaging systems are available providing improved spatial resolution for high-contrast objects. CT microscopy is currently used for imaging the trabecular bone and neovascularity. The disadvantage relative to direct projection X-ray imaging is the proportionately higher dose of radiation to which the subject is exposed. The considerably more expensive equipment and infrastructure is available within all major hospitals.

\section{Magnetic resonance imaging}

Magnetic resonance imaging (MRI) (Lauterbur 1973; Mansfield and Grannell 1973) applies a strong static magnetic field and a changing gradient magnetic field to the living subject. In addition, the living subject is exposed to an intermittent radiofrequency field. The MR signal arises from within the body once the radiofrequency is turned off. For a strongly simplified illustration of these functional principles, see Fig. 1f. The high-frequency radio waves comprising the signal are received within the scanner and decoded with respect to their spatial distribution (Callaghan 1991). As in CT, the imaging matrix consists of $512 \times 512$ small elements (pixels, voxels) representing small tissue samples within the imaging volume. Unlike ionising radiation such as X-rays, MR imaging does not cause any potentially harmful biological effects. Gradient magnetic fields allow for imaging in any plane, even sampling an isotropic 3D-volume, which may be used to navigate in real time through an organ or organ structures such as blood vessels. The strength of the magnetic field is one factor determining image resolution, and although images can be obtained with fields considerably lower than $1 \mathrm{~T}$, most major clinics work with high field strength machines, commonly $1.5 \mathrm{~T}$, though $3 \mathrm{~T}$ machines are gradually setting a new standard (Tanenbaum 2006). Other factors contributing to spatial and contrast resolution are the design of the imaging sequence, sampling rate, and signal sampling. The magnetic fields align atomic nuclei in the living subject and 
then allow them to return to non-aligned states, this "relaxation" resulting in the emission of radio waves. Special imaging sequences measure the radio waves from atomic nuclei such as phosphorus, but usually waves from hydrogen nuclei (protons) are detected as signal. Thus, in vivo monitoring of metabolism of high energy phosphorous compounds is possible. Also, diffusion of water molecules can be visualised and used for diagnostic purposes. The detector (receive coil) is arranged close to and usually surrounding the living subject, and the signals detected are processed in a computer to reconstruct the signal strengths arising from each image point (voxel) within the living subject; the resulting map of signal strengths within the imaging plane is presented as an image of a section through the subject. This imaging modality holds some surprises for the histologist. For example, the signalling medium, high-frequency radio waves, have a wavelength of approximately $7 \mathrm{~m}$, related to the fashion in which they arise, by Lamor precession of protons. The spatial resolution of the imaging modality therefore does not depend on the wavelength of the electromagnetic radiation used for the imaging. The effective spatial resolution is currently in the millimetre range. High resolution imaging of small objects is possible using dedicated MR-imagers with magnetic field strength of 5-7.5 T. MRI is an extremely flexible imaging modality. The signals emitted by protons in water differ from those emitted by protons in lipids, and this is the source of much of the image contrast in "native" images, some of the contrast arising from the paucity in some tissues such as bone. By use of appropriate imaging sequences, the signals from fats can be suppressed; so, the image becomes largely a "water image". In the presence of certain elements, gadolinium being the one that is most commonly used, the signal strength obtained from protons is amplified strongly, so that water at sites containing gadolinium emits much stronger signals. Gadolinium compounds injected into the blood therefore serve as contrast media, the blood emitting much stronger signals than the surrounding gadolinium-free tissues. The signals that are detected in MRI are relatively weak, and even in the presence of gadolinium, the water signal is not strong; the detection limit for gadolinium is approximately $10^{-5} \mathrm{moles} / \mathrm{l}$ (Runge and Wells 1995; Shellock and Kanal 1999); this renders MRI relatively insensitive, compared for example with the detection limit of $10^{-11} \mathrm{moles} / \mathrm{l}$ of PET/SPECT (Ter-Pogossian 1985) or $10^{-8} \mathrm{moles} / \mathrm{l}$ limit of fluorescence detection in light microscopy (Mason 1999). Partly, due to this relatively low sensitivity, acquisition of a full series of images requires many minutes or almost an hour. MRI does have another type of detection based on local alterations induced in the magnetic field by high susceptibility iron oxide particles, this generating a signal suppression or void rather than a positive signal (Weissleder et al. 1990; Nelson and Runge
1995), which results in a slightly better signal strength, with a detection limit of approximately $10^{-6}$ moles/l. MRI is therefore a signalling modality, which can obtain significant benefit by the signal amplification, which can be obtained by use of nanoparticles. Our own work (Paschkunova-Martic et al. 2005) has demonstrated molecular imaging of the vascular endothelial wall in the liver of mice by use of targeted nanoparticles (Fig. 2). During the next years, the sensitivity of MRI will be considerably enhanced, first by use of new technologies such as CEST (Zhang et al. 2008) and PARACEST (Woods et al. 2006), using molecular complexes whose chemical shifts generate off-resonance contrast through proton exchange, giving detection limits of $\sim 10^{-11}$ moles $/ 1$, comparable with PET/SPECT. Even higher sensitivities would become available by abandoning chemical shifts and using structured geometries to control magnetic fields within particles: lithographic and etching techniques in micro-engineering can be used to fabricate micro- and nano-structures with "tuned" geometries capable of giving detection limits down to $10^{-14}$ moles $/$, combined with spectral qualities providing MRI "in colour" (Zabow et al. 2008); geometrical properties of the nanoparticles here play an analogous role to exciton sizes of quantum dots, which generate well-defined colours. During the next few years, MRI will reach detection limits much lower than those now available by use of radio-isotopes, without toxicity and without large changes required to existing hardware. MRI is therefore a "space to watch" in molecular imaging. To complete this introduction to MRI, it should be noted that this imaging modality is associated with high capital and infrastructure costs. MRI and PET exhibit complementary imaging properties, and PET/MRI fusion facilities have been built at many centres as back-toback radiology/nuclear medicine facilities. Most recently, integrated single machines have been developed to combine the high resolution of MRI with the high sensitivity of PET, but these are available only at a small number of research centres across the world.

\section{Ultrasound imaging}

This imaging modality is relatively inexpensive and requires relatively little infrastructure, and is also highly patient-friendly. Soft tissues are largely transparent to ultrasound, but contain interfaces, which reflect ultrasound waves differentially. These are ideal conditions for imaging by use of ultrasound waves, and ultrasound imaging is a well-established imaging modality in clinical use. Spatial resolution depends on the wavelength used (currently in the range of $5-15 \mathrm{MHz}$ ). The last three decades have seen many proofs of the principle that molecular imaging can be realised by use of microbubbles in ultrasound imaging (Lindner 2002). However, nanoparticles have no role in 

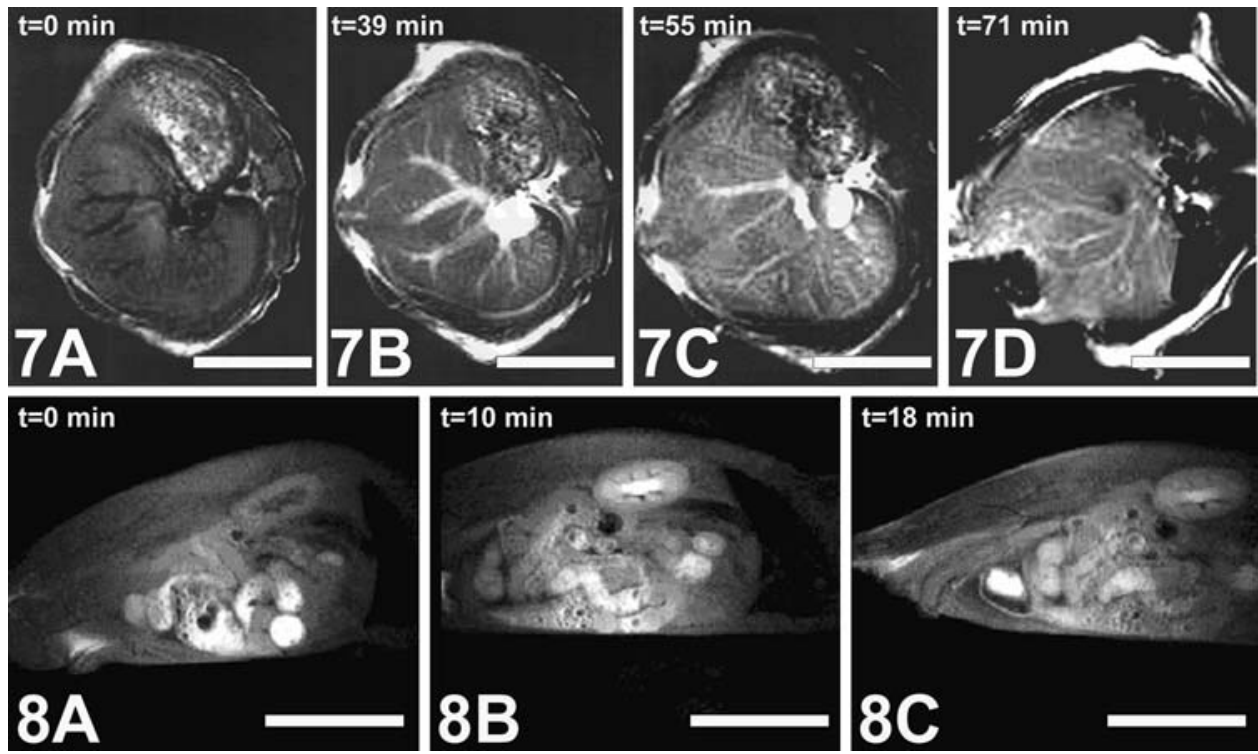

Fig. 2 In this previously published image (Paschkunova-Martic et al. 2005), we showed that latex nanoparticles bearing gadolinium-DTPA chelates as signalling groups, and tomato lectin molecules as targeting groups, adhered strongly to the vascular wall in the liver of living mice. This series of MRI images presents a time-series, beginning with time zero $(t=0 \mathrm{~min})$, an image acquired before injection of nanoparticles, and passing through $39 \mathrm{~min}$ at which time the blood of the mouse contains high concentrations of nanoparticles generating strong contrast in the blood space of the liver vessels. Fifty-five minutes after injection of the nanoparticles, a rinse with $1.0 \mathrm{ml}$ of buffer failed to clear the nanoparticles from the blood vessels. At $71 \mathrm{~min}$, we rinsed the circulatory system of the animal with $4 \mathrm{ml}$ buffer, which is double the blood

volume of the mouse, which flushed the blood space but left nanoparticles embedded in the vascular walls and these therefore appear white in the image. The resolution in these images is better than $0.1 \mathrm{~mm}$ in the image plane; the MRI machine was operated with a magnetic field of $1.5 \mathrm{~T}$ (machine normally in routine clinical use). The lower series of images shows that gadolinium-DTPA chelates (Magnevist ${ }^{\circledR}$ ) at 10 min after intravenous injection are already concentrated in the kidney, and at $18 \mathrm{~min}$ are essentially in the urinary bladder. These images demonstrate the high spatial resolution of MRI, and also the use of nanoparticles to prolong circulation time and to allow targeting to a specific tissue site. All calibration bars $1 \mathrm{~cm}$

ultrasound imaging, for physical reasons. The frequencies necessary to detect particles smaller than $1,000 \mathrm{~nm}$ diameter, exceeding $30 \mathrm{MHz}$, do not penetrate more than a few millimetres into living tissues. Furthermore, contrast media are based on air-liquid interfaces of high curvature (bubbles), and creating bubbles of nanosize is a difficult undertaking. For the foreseeable future, ultrasound molecular imaging will be carried out by use of microparticles (microbubbles, with diameters generally larger than about $5 \mu \mathrm{m}$ ). We mention this imaging modality for the sake of completeness, but it falls outside the scope of this review to provide a more detailed description. Ultrasound can however be generated by optical stimulation of structures within a living tissue, and nanoparticles can play important roles in "photo-acoustic imaging", as described above.

\section{Why nanoparticles?}

Stationary accumulation of signalling groups at specific target sites

Molecular imaging reveals the location of particular molecular types within a tissue. To obtain adequate contrast in the

image, signal-emitting materials must be accumulated in a stationary fashion at the site of the molecules. Radionuclides emit energetic signals, which provide high signal-to-noise ratios, so that attachment of a single radionuclide atom to a targeting molecule (such as antibody) allows stationary small accumulation of such molecules within a tissue to be imaged with high contrast. The accumulation of $10^{-11}$ moles of such gamma-emitting conjugates is adequate for imaging (see above). Fluorochromes emit signals approximately one thousand times weaker, so that a fluorescence image of comparable quality would require accumulation of 1,000 times more fluorochrome molecules at the site than for PET. The number of the specific target molecules at the site may not be sufficient to allow stationary accumulation of so many antibody molecules, and in this case the use of antibody molecules conjugated to a few hundred fluorochromes would be needed. A single antibody molecule will not carry more than a dozen fluorochrome molecules without loss of its specific binding, rendering use of a particulate matrix essential to carry the payload of a few hundred fluorochromes. Gadolinium chelates in water emit signals yet one thousand times weaker than fluorochromes, and in this case the use of particulate matrices becomes mandatory for successful imaging; the particles 
are conjugated with the targeting groups (such as antibodies) and bear a payload of several thousand gadolinium chelates. The contributory effects of voxel size are ignored in this discussion. As discussed below, optimised particles for most applications will be at least $20 \mathrm{~nm}$ diameter and possibly as large as $300 \mathrm{~nm}$, and will therefore fall under the definition of nanoparticles.

Occasionally, nanoparticles are not needed. For some applications, larger particles are better. An example is cell tracking by MRI. For cell tracking in vivo, MRI is the ideal imaging modality. It tracks cells throughout the entire volume of the animal, even of large laboratory animals; it has excellent soft tissue contrast, acceptable spatial resolution, and is biologically safe and uses non-ionising radiation. Tracking the migration of small numbers of cells is required for analysing cancer cell metastasis and in studies of transplantation, including tracking of stem cells. By use of optimised radio-frequency coils, specialised magnetic gradients (Heyn et al. 2006), long scan times (2 h), and high magnetic fields [Hoehn et al. (2002): 7 T; Kircher et al. (2003): $8.5 \mathrm{~T}]$, adequate signal-to-noise ratios can be obtained, allowing detection of approximately single cells loaded with nanoparticulate iron oxides (ultra-small particles of iron oxide, "USPIOs", $30 \mathrm{~nm}$ diameter); indeed, single cells can even be detected by use of a $1.5 \mathrm{~T}$ clinical scanner (Foster-Gareau et al. 2003). A significant advance was the realisation (Engberink et al. 2007) that the iron oxide particles loaded into the cells need not be nanoparticles (Benderbous et al. 1996; Wang et al. 2001; Jung 1995) but that better results could be obtained with larger nanoparticles (small particles of iron oxide, "SPIOs", $150 \mathrm{~nm}$ diameter) (Zelivyanskaya et al. 2003; Sipe et al. 1999; Metz et al. 2004), and that excellent results can be obtained by loading the cells with micrometre-sized iron oxide particles (micro-particles of iron oxide, "MPIOs") (Shapiro et al. 2005; Hinds et al. 2003; Wu et al. 2006). A basic problem of iron particles is that they cause a signal void (negative contrast), which is difficult to quantify. Thus, iron particles can only be detected efficiently if they are surrounded by tissue, which acts as a signal intense background.

At the other extreme, there are occasional cases involving extremely dense accumulations of target molecules (Artemov et al. 2003), allowing successful MR imaging by use of only few gadolinium chelates bound to each antibody molecule; in these cases, (nano)particulate carriers are not necessary. The general case, however, is that a signal amplification will be required. It is possible to use a wide range of elements for contrast generation in MRI, though all have lower relaxivities than gadolinium and would thus require more atoms per nanoparticle for imaging than does gadolinium; fluorine has been frequently used (Lanza et al. 2005).
How do nanoparticles amplify signals?

The signal generators are localised to the nanoparticles in stable fashion, for example, by covalent binding. Figure 3 shows the principle of a multifunctional nanoparticle, which serves as drug carrier, is targeted, and is decorated at its surface with numerous tightly bound gadolinium chelates to serve as signal generators. The signal emitted by
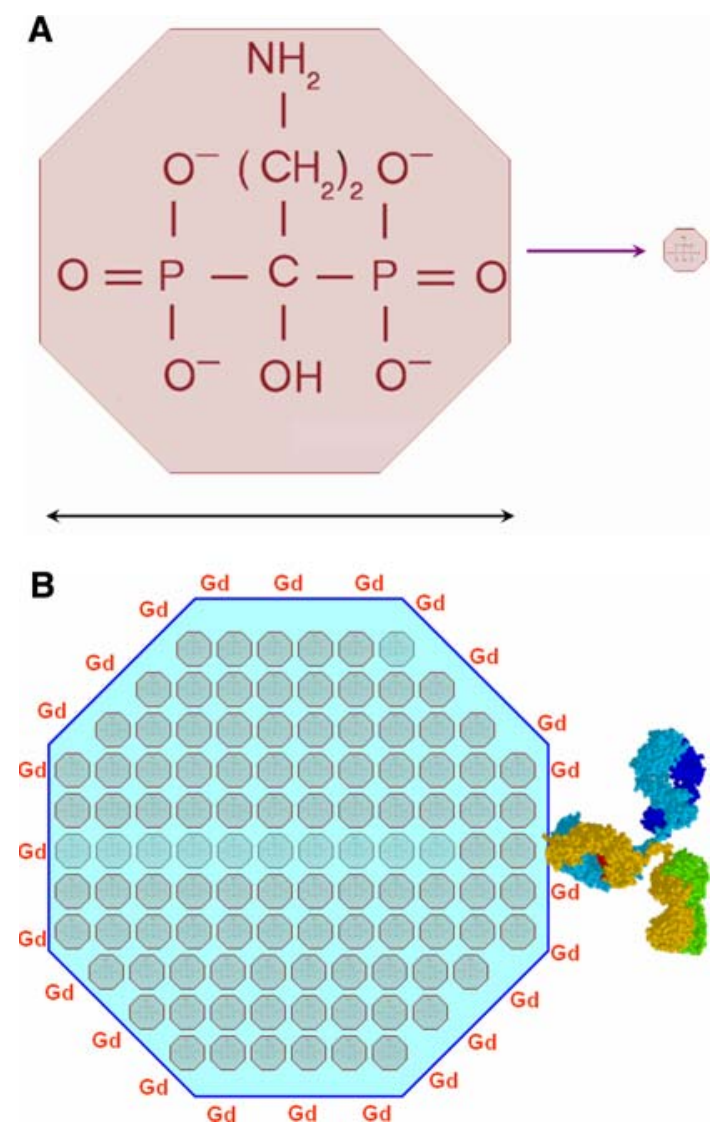

Fig. 3 a Small molecular weight drug: the drug molecule (3-amino-1hydroxypropylidene)bis-phosphonate (Pamidronate) is sketched as a particle of approximately $2 \mathrm{~nm}$ diameter, the size of many small drug molecules. At the right hand side, the pamidronate particle is shrunken to approximately the size it will occupy in (b). b Drug-bearing nanoparticle: a $25 \mathrm{~nm}$ diameter nanoparticle can enclose approximately 1,000 pamidronate molecules. Pale blue shading represents the matrix of the nanoparticle, which must be crosslinked for stability. At the right hand side, an antibody molecule, shown to scale, is attached to the nanoparticle to serve as targeting group; the linker mediating the attachment is not shown in this sketch. Around its surface, the nanoparticle is decorated with gadolinium chelates, represented here as "Gd" and approximately to scale; the linker connecting the chelate to the nanoparticle surface is not shown. The surface of the $30 \mathrm{~nm}$ diameter nanoparticle has adequate space for approximately 1,000 Gd chelates. This sketch represents an idealised multifunctional nanoparticle, serving as carrier for a drug, with a targeting function and with sufficient signal generators to provide strong signalling in MRI. The particle could be a liposome, a dendrimer, a protein particle, or one of several other particle types; the signal generator need not be gadolinium; it could be a fluorochrome or a radionuclide; there need be no drug at all, or pamidronate could be replaced by any of numerous other drugs 
such a nanoparticle is extremely strong, whereas the signal generated from the surrounding aqueous medium is close to zero; the nanoparticle has a strong signal-to-noise relationship. At the target site, there will accumulate many thousands of such nanoparticles as this, and will generate thousands of signals for each of the target molecules to which they are bound: this thousand-fold amplification arises from the small volume of the target site, and from nowhere else. In MRI, the accumulated nanoparticles must fill a considerable part of the tissue volume represented by a voxel; otherwise, the signal will be averaged out in the voxel and will not be detectable; the total gadolinium within the voxel must be close to $1 \mathrm{mM}$ for reliable detection of the signal. In this way, the nanoparticles act like a histochemical stain, which accumulates at certain sites in the tissue and provides colour or contrast at those sites, and is absent elsewhere.

Particulate carriers for molecular imaging will almost always be nanoparticles

Each functionality associated with a structure requires a certain volume of space, and a collection of functionalities needs a certain ordered spatial arrangement. An example is the human head, with its functionalities of vision, audition, olfaction, mastication, and cerebration, and which is between 20 and $30 \mathrm{~cm}$ tall. The same functionalities can be found in the smallest of the apes, a certain tarsir, with a head only $1.5 \mathrm{~cm}$ tall. It is quite likely that this is the smallest head capable of accommodating these particular functionalities. For molecular imaging, a particle requires a recognition and adhesive functionality, a signalling functionality, and a carrier functionality, as discussed earlier. These functionalities require protuberances, branches, hinges, sculpted surfaces, and other spatial specialisations, and each of these in turn must be constructed of a few hundred atoms. The immunoglobulin molecule with its two recognition sites has a gyration radius of $6 \mathrm{~nm}$, and a third functionality in the $\mathrm{Fc}$ region (activation of other immune functions) requires further several nanometres, so that the entire molecule is approximately $12 \mathrm{~nm}$ in diameter. The ribosome, with its several recognition sites and several effector sites, is $20-25 \mathrm{~nm}$ in size. The several functionalities required in a particle that should carry a few thousand gadolinium chelates, and also bear several targeting groups (such as antibody molecules), will require a volume not much less than a ribosome. It is safe to assert that such a particle will not be feasible below a size of approximately $20 \mathrm{~nm}$. It will be a small nanoparticle, and any further addition to its functions will render it larger. It does seem that a large number of functionalities, and also a large molecular payload, will fit into a nanoparticle $50 \mathrm{~nm}$ in size, which in turn will fit into an endocytotic vesicle. Viruses, which accommodate most of the functionalities required for targeted drug delivery, are frequently in this size range and not smaller.

Theranostics requires multifunctional nanoparticles

There are reasons to expect that MRI will become much more sensitive in the next few years (see below). As its sensitivity approaches and perhaps exceeds that of fluorochromes, the need for nanoparticles in MRI molecular imaging might seem to fade away. However, there is a separate reason why nanoparticles will be required even in more sensitive versions of MRI, and this is theranostics. The payload of the nanoparticle can consist of drug molecules and of signalling materials. This combination allows the nanoparticle to be located within the living subject and at the same time to release drugs into a target site, enabling molecular imaging to be combined with therapy. This "therapy" plus "diagnostics", or "theranostics" holds the promise in future of monitoring the effectiveness of therapy simultaneously with delivering the therapy, and thus of tailoring the therapy to the individual needs of a patient ("personalised medicine"). The design of a multifunctional theranostic nanoparticle is a large challenge, but it is evident that such multifunctional particles can be created successfully, because viral particles are exactly such particles.

\section{Design principles of nanoparticles for molecular imaging}

Size of nanoparticle

As discussed earlier, multifunctional nanoparticles will exceed $20-30 \mathrm{~nm}$ in size. In this size range, nanoparticles are easily taken up into cells via endocytotic vesicles, which typically are 40-60 nm diameter. Nanoparticles larger than $150 \mathrm{~nm}$ will not enter the cells by endocytosis and will be at the upper limit for passage through caveolae; they will be phagocytosed by macrophages and therefore routed via the reticulo-endothelial system to lymph nodes and the spleen. These considerations suggest a size between 30 and $150 \mathrm{~nm}$ diameter for nanoparticles to be used in molecular imaging, and this size also permits drug payloads of several tens of thousands of drug molecules within each nanoparticle.

\section{Number of targeting groups}

In immunohistochemistry, an antibody molecule binds specifically to its antigen within a tissue section, thus targeting itself, plus a payload consisting of a peroxidase enzyme molecule, into a specific antigenic site. The anti- 
body-peroxidase complex is approximately $20 \mathrm{~nm}$ in size, with a mass not exceeding $300 \mathrm{kDa}$. A nanoparticle of $50 \mathrm{~nm}$ diameter is much heavier, with a mass close to $40 \mathrm{MDa}$ if it consists of a polymer matrix. A single antibody molecule attached to such a nanoparticle may not develop sufficient binding force to anchor the large mass to a target antigenic site. Furthermore, in immunohistochemistry, the antibody-enzyme complex is applied in a non-turbulent environment and incubated for long periods of many minutes to facilitate adhesion to its target antigen. In the bloodstream of a living animal, the environment is turbulent and an antibody-targeted nanoparticle may come into close contact with a target molecule for only a few seconds: a bond formed between the antibody and its antigen may not be strong enough to halt the motion of the nanoparticle and to anchor it to that specific site. To multiply the adhesive power of the nanoparticle, it is necessary to attach many antibody molecules to it, which by binding to the antigen in rapid succession will slow down the moving nanoparticle and eventually anchor it to that site. As a result, the targeted nanoparticle will roll along its targeted surface, in a fashion comparable to leucocytes rolling on an endothelial surface at the initiation of the inflammatory process; this comparison is not perfect, because the leucocyte weighs $\left[(8,000)^{3} \mathrm{~nm} /\right.$ $(25)^{3} \mathrm{~nm}$ ] 30 million times more than the nanoparticle and binds via the attachment of billions of specific adhesion molecules. A more exact comparison is with the natural targeted nanoparticles, the viruses. A T4 bacteriophage is about $30 \mathrm{~nm}$ in size and adheres via six "legs" to its target, each leg bearing an adhesive site at its "foot". The wildtype HIV viral particle, about $130 \mathrm{~nm}$ is diameter, bears 14 targeting spikes, which is about one spike per $3,000 \mathrm{~nm}^{2}$ of surface area. Following the natural example, a designer of artificial nanoparticles might plan to attach ten antibody molecules to the $50 \mathrm{~nm}$ nanoparticle (one antibody molecule per $250 \mathrm{~nm}^{2}$ of surface area) to ensure its stable anchorage at the target site. Since antibodies are expensive, natural selection amongst nanoparticle designers will ultimately help determine the minimum number of antibody molecules necessary to tether a nanoparticle to its antigenic site.

\section{Number of signalling groups}

In different imaging modalities, one signalling group per particle may be enough, although that signalling group functions in quite different ways in the different modalities. In PET, one or two radionuclide atoms per particle are adequate for strong signalling. In fluorescence microscopy, the nanoparticles, known as quantum dots, each contain one exciton. In MRI, SPIOs are $150 \mathrm{~nm}$ nanoparticles consisting of a single signalling group. In photo-acoustic imaging, a single metal nanoparticle suffices to generate the necessary signal. However, in the case of organic fluorochromes or of gadolinium-contrasted MRI, numerous signalling groups are attached to each nanoparticle. As described above, the required number is related to the sensitivity of the detection in any given modality. For fluorochromes, a few hundred per particle is adequate, but for MRI the particle should carry a few thousand gadolinium chelates $(\mathrm{Gd}$ chelates). Since gadolinium-enhanced contrast requires free diffusion of protons, the particles must be water-permeable if they contain $\mathrm{Gd}$ chelates distributed throughout their volume.

\section{Mechanical properties}

For survival within the turbulent dynamics of the bloodstream, a nanoparticle requires a certain mechanical integrity. Nanoparticles held together only by charge-based forces will certainly be disrupted rapidly. Crosslinking by covalent bonds lends the necessary stiffness and cohesion to survive bloodstream turbulence, and also guarantees the stability of the nanoparticle at the target site, where stationary accumulation of stable nanoparticles is essential for molecular imaging. However, a nanoparticle can be so stable that its clearance from the organism is possible only by macrophages, which prolongs the duration of exposure to any toxins (such as gadolinium) that are present in the nanoparticle. An ideal signalling nanoparticle would remain intact at the target site (and nowhere else) until its molecular imaging role is fulfilled, then disintegrate rapidly and vanish from the organism within hours, for example, by renal excretion; such nanoparticles are not available yet.

\section{Surface decoration}

Nanoparticles of any size are foreign bodies in the blood, and therefore liable to clearance via macrophages and the reticulo-endothelial system. The larger the particle, the more likely this will be, but all nanoparticles require an ability to evade the immune system. To evade uptake by macrophages, they may be decorated with small polymers of polyethylene glycol ("PEGylated"), lending them the characteristic known colourfully in the literature as "stealth" (Moghimi et al. 2001; Moghimi and Szebeni 2003).

It is evident that the design and construction of a nanoparticle satisfactory in all the above respects is a major task in several fields of chemistry, and requires detailed knowledge of the working environment, the organism, in which the nanoparticle must eventually mediate molecular imaging. This review returns to these matters below. 


\section{Physical realisation of nanoparticles}

The nanoparticle matrix

\section{Liposomes}

Liposomes are the most mature form of nanoparticles (Mulder et al. 2005); development of these began in the 1970s (review by Drummond et al. 1999). They consist of amphiphilic compounds (phospholipids, glycolipids, and aminolipids) formed into membranes (Hofheinz et al. 2003), enclosing aqueous cavities (Fig. 4). Some are approved for clinical use, including PEG and non-PEG liposomal doxorubicin for metastatic breast cancer, and PEG liposomal doxorubicin and liposomal daunorubicin for Kaposi sarcomas (see Hofheinz et al. 2003). Liposomal nanoparticles are popular substrates for use in development of targeted nanoparticle systems, for example, as immunoliposomes targeted by antibodies or antibody fragments.

\section{Metal oxides}

Metal oxides are long-established substrates for nanoparticle production (Weissleder et al. 1990). Superparamagnetic iron oxide (SPIO) nanoparticles exhibit extremely high relaxivity. Such a particle consists of magnetite core surrounded by a matrix material such as dextran (Fig. 4). The distortion, which the core causes in the magnetic field, leads to hypo-intensities in $\mathrm{T}_{2}$ - or $\mathrm{T}_{2}$-weighted images, the image areas containing SPIOs therefore showing low signal intensity ("negative contrast"). The signal void due to the large magnetic susceptibility of a SPIO is much larger than the particle size, enhancing detectability. In addition to uses in molecular imaging, involving attachment of targeting groups to the SPIOs, these particles have been used to track numerous cell types (Dodd et al. 1999; Cunningham et al. 2005), including $\mathrm{T}$ lymphocytes (Kircher et al. 2003), macrophages (Engberink et al. 2007), and stem cells (Frangioni and Hajjar 2004; Partlow et al. 2007). Although there are claims of detection at $10^{-12} \mathrm{M}$ ( $\mathrm{Gao}$ and Hillebrenner 2008), present-day technologies involve a trade-off between the SPIO imaging parameters including field strength, gradient characteristics, acquisition time (Kircher et al. 2003; Heyn et al. 2006) against the number of cells to be detected. Also there are differences in detection sensitivities between SPIOs and the ultrasmall SPIOs (USPIOs) (Engberink et al. 2007). Nano- and microparticles in the form of iron oxide particles are available commercially in streptavidin-conjugated form and can be used to target tumour cells (Artemov et al. 2003). The conjugation of drugs to the surface of iron oxide nanoparticles has been reported (Hung et al. 1990), but as with the metal nanoparticles, large amounts of drugs cannot be

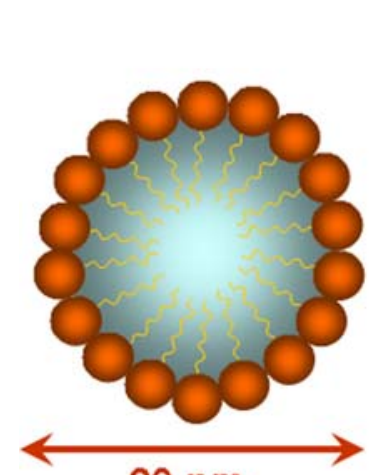

$20 \mathrm{~nm}$

\section{Liposome}
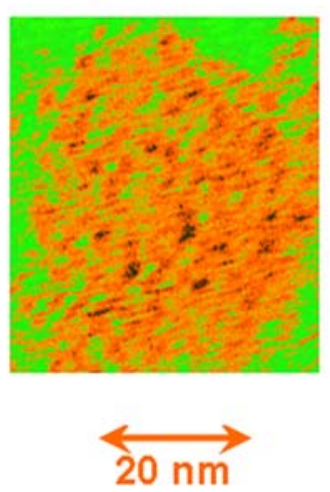

Protein particle

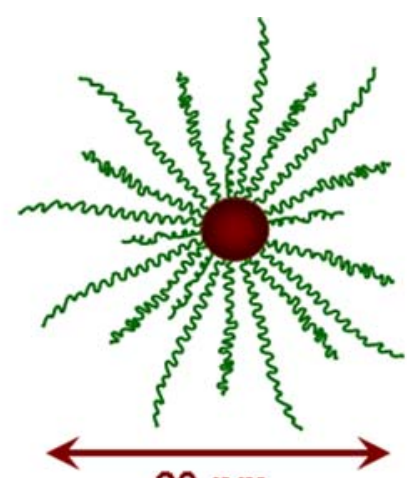

$20 \mathrm{~nm}$

\section{USPIO}

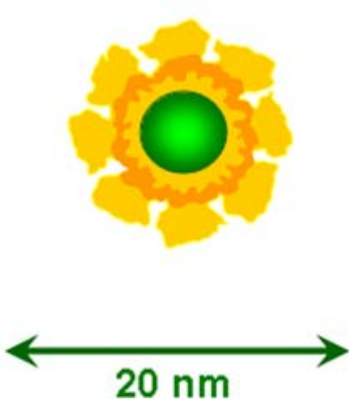

Quantum Dot
Fig. 4 Three forms of nanoparticles are sketched and one form is shown as an electron micrograph. The simplest form of liposome consists of a micelle with hydrophoblic lipid components at the surface, and hydrophilic chains projecting into the water-filled internal cavity. A liposome of this size can already carry hundreds of small drug molecules, either within the water-filled cavity or within the lipid shell, or aligned between the water- and lipid-environments. Typically, liposomes are PEGylated at their outer surfaces, and targeting groups such as antibodies, aptamers, or peptides can be attached (not shown). Liposomes can be constructed in much more complex versions, for example, as multilamellate bodies, which are considerably larger: liposomes larger than $200 \mathrm{~nm}$ diameter are often reported. An ultrasmall particle of iron oxide (USPIO) is sketched: the iron oxide particle (brown) is 4-6 nm diameter and is derivatised with polymer chains (green); dextran is frequently used for this, chitosan is another of the numerous alternatives. To these chains can be attached targeting groups (not shown). A protein-based (albumin) nanoparticle prepared in our laboratory is shown as an electron micrograph. The Eponembedded particle was imaged non-osmified, and the greyscales assigned false colours. The amorphous protein structure, shown red, encloses numerous water-filled internal cavities (green), which provide pathways for molecule exchange, for example, of any drugs that the albumin could be transporting. A quantum dot is sketched. The central semiconductor crystal (green), about $5 \mathrm{~nm}$ diameter, is coated with several layers (shades of orange and yellow), which may include silica, proteins, and peptides, and which protect the crystal from the surrounding aqueous environment. They also provide attachment sites for targeting groups. The precise diameter of the crystal determines the colour of the light it emits. The dot shown here is simple, but more complex core/shell arrangements of two crystal types are used to produce dots with emissions at longer wavelengths, for example, in the infrared 
incorporated per nanoparticle. Metal oxide nanoparticles based on metals other than iron have been used to perform vaccination, based on oligopeptides attached to any of the range of metal oxide nanoparticles, including the particles (Frey et al. 1997, 1998).

\section{Dendrimers}

Dendrimers are built up as molecules from small subunits attached to one another in successive stages or generations, leading to extremely large structures of nanoparticle size (Kobayashi et al. 2005; Bulte et al. 2001). As substrates for nanoparticle production, they have several advantages, including the high level of control over architectural design and molecular weight, chemical composition, size, shape, branching length/density, and surface functionality. Simplification of their synthesis, by the "lego" and "click" approaches, has reduced their costs of production (Svenson and Tomalia 2005). Control over their size and composition allows predictable tuning of their biocompatibility and pharmacokinetics (Lee et al. 2005). They have been used in imaging of lymph nodes in cancer (Kobayashi et al. 2005) and to track stem cells (Bulte et al. 2001), but these applications were not targeted and represent precursor developments for molecular imaging.

\section{Polymers}

Polymers are a further popular substrate for creation of nanoparticles. Much research has aimed to conjugate drugs into polymers, producing copolymers such as the $\mathrm{N}$-(2hydroxypropyl)methacrylamide (HPMA)-doxorubicin conjugate PK1 (Vasey et al. 1999), and other HPMAcopolymer conjugates, some useful in imaging (Duncan 2005). Polyglutamic acid (PGA)-paclitaxel copolymer (CT-2103) (Xyotax) is entering the market as cancer treatment for non-small-cell lung cancer in women (Singer 2005). Polyethyleneglycol in conjugation with camptothecin (EZ-246, Pegamotecan) (Posey et al. 2005) and cyclodextrin in conjugation with camptothecin (Schluep et al. 2006a, b; Zamboni et al. 2006) are entering clinical trials. Polymer-drug conjugates are being directed not only against tumour cells, but also against angiogenic blood vessels, for example, HPMA-fumagillol (TNP-470) caplostatin (Satchi-Fainaro et al. 2004; Huang et al. 2004; Inoue et al. 2003; Bhujwalla et al. 2003), the HPMA copolymerRGD4C-Tc-99m conjugate, capable of targeting tumour angiogenic vessels and delivering adequate radiotherapy to arrest tumour growth (Mitra et al. 2006) and PEGylated cyclic arginine-glycine-aspartic acid (RGD) radiotracers (64-Cu-DOTAPEG-RGD and 125 I-RGD-mPEG) targeted at integrins (Chen et al. 2004a, b). The emphasis in work on polymer-drug copolymers lies at present on drug delivery, but attachment of signal generators to these copolymeric nanoparticles is of considerable interest, because this would allow real-time monitoring of drug biodistribution and action. For reviews of this active field, see Duncan (2005) and Vicent (2007). Carbohydrate polymers such as chitosan (Agnihotri et al. 2004) and dextran (Dhaneshwar et al. 2006) have been used to enhance the solubility, lymphatic uptake, and physiological acceptance of both enzymes and drugs. Latex polymer nanoparticles have been used to demonstrate the vascular wall by molecular imaging (Paschkunova-Martic et al. 2005).

\section{Proteins}

Proteins are further major matrices for nanoparticles. Albumin, as the body's major transporter molecule, is being formed into nanoparticles (Fig. 4), incorporating several major types of drug, for which it improves biocompatibility, bioavailability, and safety (see below). Gelatin nanoparticles are also under investigation (Balthasar et al. 2005; Wartlick et al. 2004), building on the long series of investigations that have been carried out into controlled release from this protein. Natural protein complexes or "protein cages" have also been employed (Flenniken et al. 2006).

\section{Quantum dots}

Quantum dots are semiconductor materials prepared in nanoparticle form (Fig. 4), varying in size slightly to tune their emission wavelengths to different values (Bakalova et al. 2007). They exploit a quantum effect related to particle size, which retains incoming energy inside the particle in the form of "excitons". The energy of the exciton is determined by its wavelength and this, in turn, is constrained by the size of the particle. When the energy of the exciton is emitted from the particle, it appears as a photon of precisely defined wavelength, so that quantum dots generate extremely pure monochromatic emitted light (Fig. 5a). They also do this with extremely high quantum efficiencies, which can exceed $60 \%$. For these reasons, they provide powerful emission for use in fluorescence microscopy, and since the emission depends on physical parameters of the quantum dots, it is stable: it does not bleach (though the dots may blink), and does not depend on environmental parameters such as $\mathrm{pH}$ value. They are available commercially in a range of pure colours, and since quantum dots do not have absorption maxima but rather can be excited by use of a range of wavelengths, all the colours can be visualised simultaneously by use of a single light source. They provide excellent substrates for optical imaging of tumours (Gao et al. 2004; Wu et al. 2003; Lidke et al. 2004; Lee et al. 2008) and can be coated with amphiphilic block copolymers with drug delivery functionalities (Gao 
Fig. 5 a The physical size of the crystal cores, which lie at the heart of quantum dots, is the parameter, which determines the energy of the exciton contained within the dot, and therefore the pure colour of the light, which the dot emits. Since the light emitted when an exciton gives up its energy is monochromatic, the dispersity of the colour emitted depends upon the size dispersity of the dots. Commercial dots are almost monodisperse, allowing several colours to be emitted within the visible spectrum, from dots with cores of 2.0 $5.0 \mathrm{~nm}$. b The chemistry of quantum dots couples together elements from Groups II/VI, IV/ VI, and III/V of the Periodic Table, as shown here connected by lines. The radioactive members (lightning symbol) of the groups are not employed. However, the majority of combinations used to create quantum dots contain at least one toxic partner (danger symbol), and several consist of two toxic elements

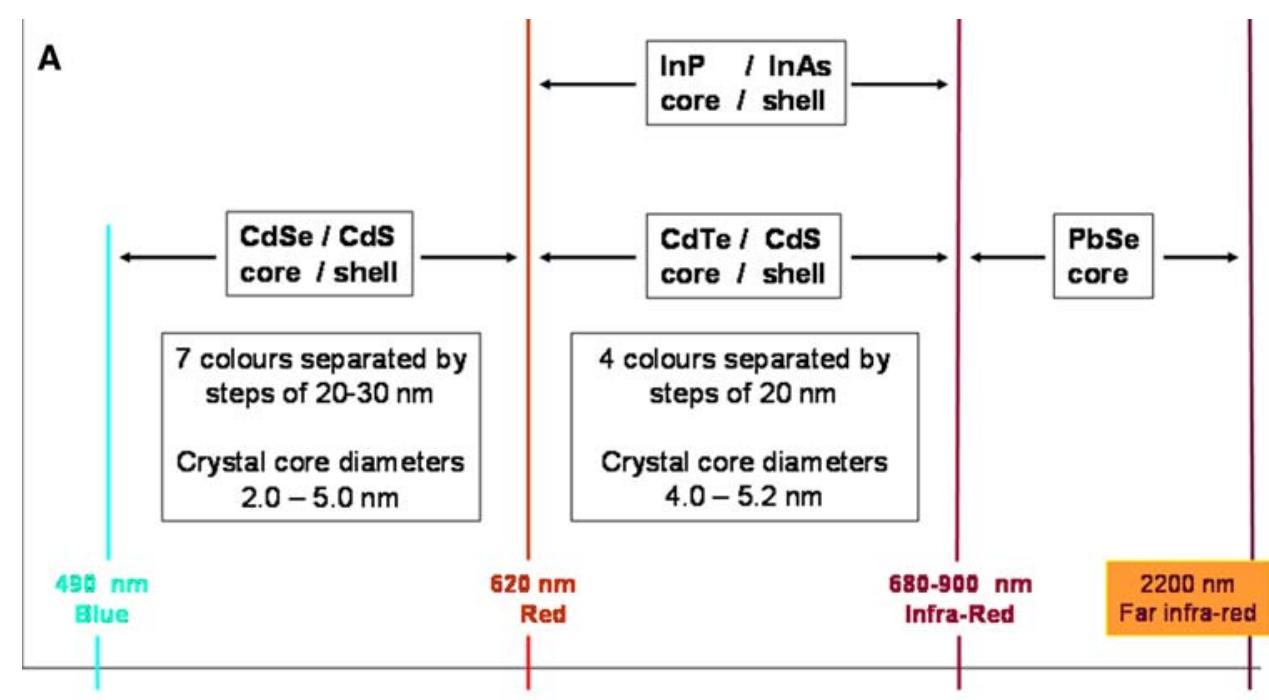

B

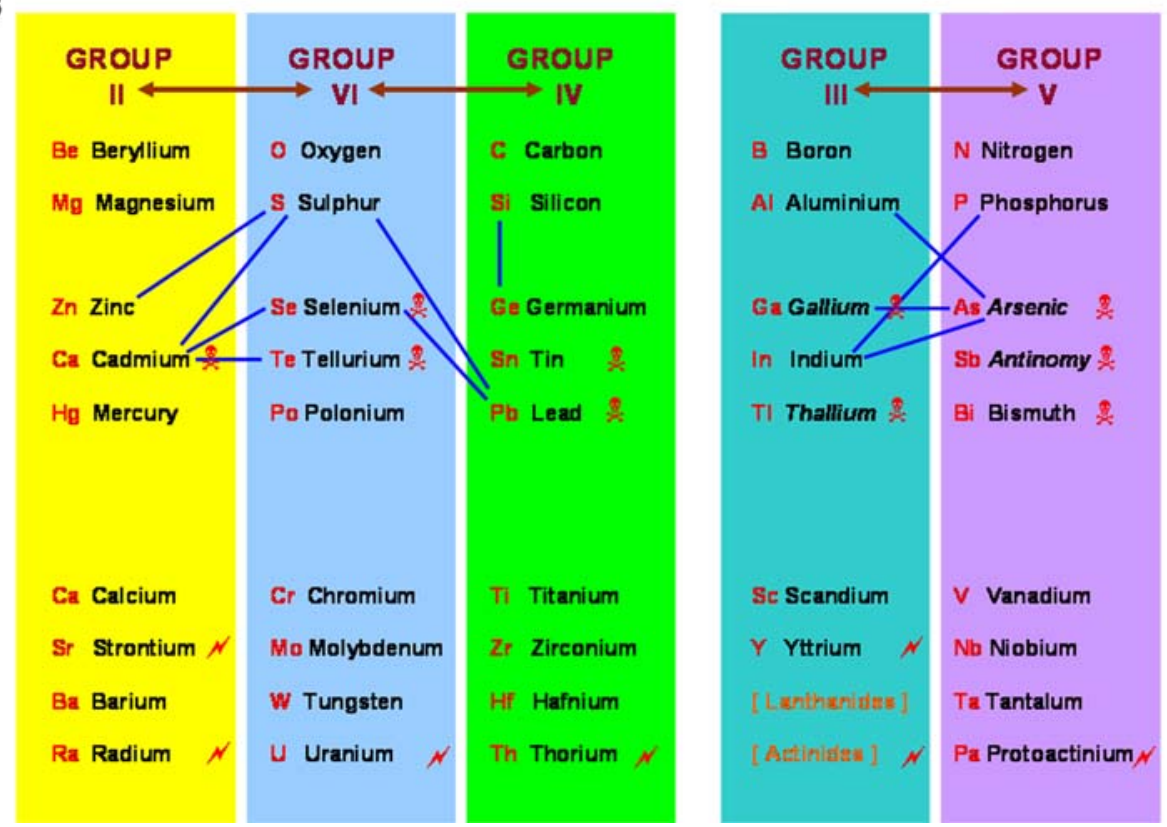

et al. 2005). However, they are a varied group of substances containing frequently toxic cores (Fig. 5b), which may be exposed by oxidative, photolytic, and mechanical instabilities (Hardman 2006). They are thus intrinsically unsuited to targeted drug delivery, because any dissolution of the outer shell (in which the drug must be loaded) exposes the toxin core, but have important applications in histopathological diagnostics (Xing et al. 2007).

\section{Metals}

Gold nanoparticles offer considerable advantages in terms of standardisation and toxicological properties. They are excellent substrates for optical imaging (Chen et al. 2005; Elghanian et al. 1997) and photoacoustic imaging (Copland et al. 2004). They have been used for true molecular imaging based on attachments of aptamers to visualise cancer cells (Huang et al. 2008a). Silver nanoparticles also exhibit extremely interesting optical properties (Haes and Van Duyne 2002) and can be considered for targeted molecular imaging. Bismuth nanoparticles have been developed for use in X-ray CT imaging (Rabin et al. 2006), and like gold nanoparticles, might be considered for use in targeted molecular imaging.

\section{Viruses}

Viruses and their capsides offer potentially highly differentiated nanoparticles for attachment of specific targeting groups and may have an important role in future molecular imaging (Allen et al. 2005; Lewis et al. 2006). 


\section{Carbon-based nanoparticles}

Carbon-based nanoparticles such as fullerenes (Bosi et al. 2003; Fatouros et al. 2006; Oberdörster 2004) and nanotubes (Gao and Hillebrenner 2008; Pagona and Tagmatarchis 2006) are under development as contrast agents that can easily be decorated with targeting groups, but exhibit some unfavourable toxicological properties, especially the nanotubes.

All the various material versions of nanoparticles share the advantages of nanosize, but their suitabilities for different applications depend on their chemistries and pharmacological tolerance. Matching nanoparticle types to clinical applications depends on the core chemistry, but also on the capacity for multiple functionalisation, standardisation, adjustment of particle stability, and expense of components. Targeting groups attached to the nanoparticles can include antibodies or antibody fragments, peptides, aptamers, and nucleotides. Smaller groups such as peptides offer design advantages. The types of linkers presently in use, generally maleimide, biotinylation, carbodiimide, are not optimal and new possibilities are being explored. Signalling groups include gadolinium, fluorine, or iron oxides for MRI and gold clusters or organic fluorochromes for optical imaging. Particularly interesting are "molecular beacons", which emit signals only after interacting with a target (Massoud and Gambhir 2003), considerably enhancing contrast.

\section{The targeting groups}

In molecular imaging, the targeting groups play the central role of mediating adhesion to the target sites. To do this reliably, they should exhibit exquisite specificity and high affinity binding at the targets. The major types of targeting groups presently in use are antibodies and their derivatives, oligonucleotides in the form of aptamers, and specific ligands. Much of the development work is conditioned by two factors, namely immunogenicity and the capacity of the targeting groups to access all the targets present in the organism. Both these factors are exemplified well in the history of antibody molecules and their derivatives.

\section{Antibody molecules}

Antibodies, long used in immunohistochemistry, are ideal targeting agents. This was foreseen by Ehrlich (1900), who forecast that they would serve as "magic bullets", a promise only now being realised, 100 years later. They combine specific recognition of epitopes with high affinity binding to them. Antibody molecules have undergone extensive development by genetic engineering since 1985, and the reagents derived from them, the novel possibilities of generating human antibodies and antibody fragments without humans, and of generating entirely new and clinical relevant antibody specificities without immunisation are traced out in the following. Intact antibody molecules have often been used to target nanoparticles, but their relatively large size of about $12 \mathrm{~nm}$, and the immunogenicity of their $\mathrm{Fc}$ region, mandates use of antibody fragments rather than intact antibody molecules.

\section{Rodent monoclonal antibodies}

The capacity to recognise and home in on a single particular epitope requires monoclonality of the antibody, which then can be prepared in a purified and standardised form suitable for pharmaceutical application. Soon after Köhler and Milstein (1975) presented protocols for production of monoclonal antibodies (mAbs), development of mAbs as drugs began; the first mAb approved by the FDA for clinical application being the murine monoclonal antibody Muromonab CD3 (OrthoClone OKT3 ${ }^{\circledR}$ ) (Thistlethwaite et al. 1984) in 1986; other examples include Ibritumomab $\left(\right.$ Zevalin $\left.^{\circledR}\right)$ and Tositumomab $\left(\right.$ Bexxa $\left.^{\circledR}\right)$, both used as therapies for non-Hodgkin's lymphoma; currently more than 20 FDA-approved $\mathrm{mAb}$ therapies exist, with hundreds more undergoing clinical trials (Waldmann 2003). However, a considerable amount of further development has been necessary to achieve full benefits from mAbs (Gavilondo and Larrick 2000). It is difficult to obtain human antibody responses to autologous antigens, and immunising human donors raises ethical problems. There was general failure to develop human hybridomas or to immortalise human B cells by use of viruses; only in 2001 was successful generation of a human myeloma cell line for hybridoma production reported (Karpas et al. 2001). Development therefore focussed on improving rodent mAbs, and this was carried out in a number of stages. Production of recombinant murine antibodies was followed rapidly by partial humanisation of the antibodies, which replaced the murine $\mathrm{Fc}$ region with human $\mathrm{Fc}$. A more complete humanisation was then achieved by replacing the murine $\mathrm{Fc}$ framework regions with human Fc framework regions. This sequence of development has resulted in a mixed variety of antibodies in clinical use, derived from each stage of this development procedure; $\mathrm{mAbs}$ from each stage of the development were used to target nanoparticles. The use of humanised antibodies will increase in future, but mAbs from each stage of the developmental process were used to target nanoparticles. Many investigations aimed to use the targeted nanoparticles to deliver drugs, packing thousands of drug molecules into the nanoparticles and attaching antibodies or scFvs to target them. This approach has been furthest developed 
with immunoliposomes (Schnyder et al. 2005), for example, immunoliposomes doubly targeted to transferrin receptor and insulin receptor and bearing antisense mRNA against the epithelial growth factor receptor (Zhang et al. 2002), and anti-transferrin receptor $\mathrm{scFv}$-immunoliposomes $(\mathrm{Xu}$ et al. 2002).

\section{Rodent recombinant monoclonal antibodies}

At present, most mAbs are generated from rodents, in which it is easy to obtain strong immune responses to human antigens. The rodent origin of the mAbs however, in its turn, raises problems with human immune responses to rodent proteins after repeated application in patients. Major problems were encountered with the clinical use of mAbs due to strong "antiglobulin" immune responses (Isaacs 1990) to the non-human (rodent) sequences they contain (Kabat et al. 1991). These responses reduce serum half-life, block antibody activity, and cause allergic reactions or, in the worst case, anaphylaxis (Stern and Herrmann 2005) and necessitate patient preparation with corticosteroids. They peak 8-20 days after first application, limiting first treatment to 10 days and, due to rapid onset of a secondary response, preventing retreatment later (Routledge et al. 1993). Such nanoparticles will be useful in biomedical research, but since less immunogenic antibody fragments are available they will not find application in clinical diagnostics.

\section{Partly humanised rodent monoclonal antibodies}

In answer to the problems encountered with rodent recombinant $\mathrm{mAbs}$, considerable effort was invested in antibody gene engineering. The results were firstly chimaeric and later humanised antibodies. In a series of developmental engineering steps, murine mAbs were modified to reduce their immunogenicity, to increase their half-life in the body, and to enhance their recruitment of effector functions in the human body. As first step, recombinant chimaeric genes were constructed, which contained exons encoding $\mathrm{mAb}$ variable regions from rodents and constant regions from humans (Boulianne et al. 1984; Morrison et al. 1984). The resulting antibody is $\sim 65 \%$ human, reducing antigenicity caused by the murine $\mathrm{Fc}$ region and thereby increasing serum half-life. Genetically engineered immunoglobulins are increasingly being approved for clinical use and undergoing clinical trials beyond Phase I (Stockwin and Holmes 2003; Gavilondo and Larrick 2000). An example of a chimaeric mAb is Rituximab (Rituxan ${ }^{\circledR}$ ), an anti-CD20 used in therapy of chronic lymphocytic leukaemia (CLL) (Nabhan et al. 2003). Chimaeric mAbs are being superseded by humanised rodent mAbs; so, they are unlikely to find application in diagnostic molecular imaging of humans.

\section{Humanised antibodies}

Crystallographic analysis of $\mathrm{mAb}$ variable (V) regions revealed three hypervariable loops per domain; these "complementarity determining regions, CDRs" being the structures required to bind the epitope and these CDRs being embedded in more conserved "framework regions". Residual immunogenicity is retained in chimeric mAbs, because they contain murine $\mathrm{V}$ region frameworks and CDRs. Antibody engineering technologies were therefore used to replace the murine framework regions with human framework regions. Such constructs minimise the nonhuman contribution to the $\mathrm{mAb}$ to $\sim 5 \%$, retaining only the minimum essential rodent sequences required for epitope recognition; these constructs are termed "humanised mAbs", examples include Alemtuzumab (Campath ${ }^{\circledR}$ ), an anti-CD52 (pan-lymphocyte) antibody used in the therapy of CLL, and Trastuzumab (Herceptin $\left.{ }^{\circledR}\right)$, used in the therapy of breast cancer. The development of the Campath antibody (Alemtuzumab) from Campath-1M (rat IgM) to Campath$1 \mathrm{G}$ (rat IgG-2b) and then to Campath-1H (human IgG- $\gamma 1$ ) was reviewed by Routledge et al. (1993), discussing the trade-offs between maximising the antibody affinity and the degree of humanisation of the framework regions (i.e., affinity against immunogenicity). The trade-off is necessary because humanised $\mathrm{mAbs}$ have significantly lower affinities than the parent molecules (Carter et al. 1992; Presta et al. 1993; Riechmann et al. 1988; Hofheinz et al. 2003; D'Amato 2003). Techniques used to raise the affinity include introducing mutations into the CDRs (Chotia et al. 1989), chain-shuffling, randomisation of CDRs, and sitespecific mutagenesis (Waldmann 2003). A fully non-immunogenic $\mathrm{mAb}$ is not attainable for all patients, because the human $\mathrm{Fc}$ region is coded by different alleles carrying allotypic markers, to which antiglobulin responses can occur (van Loghem 1986). It should be noted that humanisation is not predictive of the "humanness" of the mAbs, which can only be assessed by comparing the sequence homologies (Routledge et al. 1993).

\section{Human antibodies}

Human or humanlike mAbs can be obtained in several ways: by transforming B cells from immune human donors (Karpas et al. 2001), by PCR cloning and phage display from immune human donors, by expression and selection from synthetic phage libraries of human $\mathrm{V}$ regions (Winter et al. 1994), and finally by immunisation of transgenic mice bearing human germline gene segments (Mendez et al. 1997; Kellermann and Green 2002; Hudson and Souriau 2003; Bruggemann and Neuberger 1996). The mAbs bear the Fc region with its immunogenic variability; so, these antibodies can cause immune reactions in a small minority 
of people. This discourages use in diagnostic molecular imaging.

\section{Antibody fragments}

Targeting to tissues such as solid tumours presents the challenge of overcoming multiple barriers, as discussed below. Antibodies are approximately $150 \mathrm{kDa}$ in size and are therefore cleared slowly from the blood pool; this leads to significant accumulation in normal organs and relatively limited delivery to lesions such as tumours (Colcher et al. 1998). Only seldom is there a report of good penetration of mAbs into a bulky solid tumour (Scott et al. 2005). The relatively poor targeting efficiency of intact mAbs may fall to zero in the case malignant cells located behind barriers, which are not reached and therefore survive the treatment. Use of small fragments of the antibody molecule such as Fabs and Fvs improves penetration into target tissues: Fab' fragments (molecular weight $\mathrm{MW} \sim 50 \mathrm{kDa} ; \sim 6 \mathrm{~nm}$ in size) and $\mathrm{Fv}$ (variable region fragments, $\mathrm{MW} \sim 25 \mathrm{kDa}$, $\sim 3 \mathrm{~nm}$ in size) are cleared much faster from the blood than are intact IgG molecules, and penetrate tissues much more effectively (Colcher et al. 1998). Earlier use of proteases to generate $\mathrm{mAb}$ fragments has been replaced by molecular cloning and expression of the variable region genes (V region genes) of IgG, connecting genes encoding for heavychain and light-chain variable regions at the DNA level by an oligonucleotide linker. The single-chain fragments $(\mathrm{scFv})$, which are produced, cannot recruit immune effector functions. Intact IgG molecules have two $\mathrm{Fv}$ chains, but scFvs have only a single binding site; so, their binding affinity is less than that of the parent molecules. The scFv with its faster clearance and lower affinity results in a lower effective dose at the target site, as compared to the divalent IgG molecules; this must be compensated by a higher signal generation in the functional load. It is likely that $\mathrm{scFv}$ generated by phage display will be used in future to steer nanoparticles to their targets, because they can be engineered to induce no immune response.

\section{Phage display for single-chain antibody fragments}

The obvious future significance of the phage display technique warrants a brief description here. It allows antigens to be targeted by scFvs without need for immunisation of a host animal (Smith et al. 2004). The technique was first described by McCafferty et al. (1990). Large repertoires of heavy and light chain $\mathrm{V}$ regions are created as DNA sequences amplified by polymerase chain reaction from immunised humans (Cai and Garen 1995) or animals (Chester et al. 1994). These V-chain sequences are spliced to the gene sequence for a phage-coat protein. Expression of the spliced DNA segments results in $\mathrm{scFv} /$ phage-coat fusion proteins expressed at the bacteriophage surface. The phage particles are secreted into the culture medium, without lysis of the bacterial cell, and display at their surfaces $\mathrm{scFv} /$ phage-coat fusion proteins capable of recognising and binding an epitope of the desired antigen. Phage carrying $\mathrm{V}$ genes encoding binding activities can then be selected directly with antigen by several rounds of affinity binding, allowing rapid screening of large libraries of potential binding activities. The derivation of scFvs from humans results in targeting groups of low immunogenicity, of great potential use for attachment to nanoparticles destined for clinical use in diagnostic molecular imaging.

\section{Entirely synthetic antibody fragments}

The $\mathrm{V}$ region repertoires need not be derived from immunised animals but can be created by randomised permutation (Vaughn et al. 1996); in this way, the technology has become available to generate libraries of $\mathrm{V}$ region genes without immunisation, and to screen them for utility as targeting agents directed to any desired antigen. This bypasses immunisation strategies. No animals are needed and production is rapid. scFvs can replace intact antibodies in both research and clinical applications; the first to enter clinical use was MFE23, specific for carcino-embryonic antigen (Chester et al. 1994). An interesting example is an anti-VEGF scFv (Vitaliti et al. 2000; Smith et al. 2005; for review, see Smith et al. 2004).

\section{Oligonucleotides (aptamers)}

Aptamers are small synthetic nucleic acid molecules, either DNA or RNA, with molecular weights as low as $5-10 \mathrm{kDa}$, which act as ligands binding to proteins (Brody and Gold 2000) or to small molecules including metabolites (Ohsawa et al. 2008). They can be screened rapidly, efficiently, and automatedly by the SELEX screening procedure ("systematic evolution of ligands by exponential enrichment") to select sequences optimal for binding to a particular target (Tuerk and Gold 1990; Ellington and Szostak 1990; Tian 2002). They can identify single proteins of interest in complex mixtures derived from whole cells (Morris et al. 1998; Daniels et al. 2003), for example, recognising single proteins expressed in tumour microvessels but not normal microvessels (Blank et al. 2001). The SELEX technique can be applied to "difficult" targets such as large transmembrane molecules, generating aptamers capable of blocking specific intracellular signalling pathways (Cerchia et al. 2005). They are therefore excellent tools in cancer research and therapy (Shangguan et al. 2006) and in cardiovascular research and therapy (Keefe and Schaub 2008). They can bind to pathogens such as trypanosomes (Homann and Goringer 1999; Ulrich et al. 2002; Adler et al. 2008), 
Salmonella (Pan et al. 2005), or influenza (Jeon et al. 2004), blocking their adhesion to their target cells. Their advantages as targeting agents include their rapid and inexpensive chemical synthesis, which results in high homogeneity, an important characteristic for quality control. They are stable over long-term storage at ambient room temperature. Unlike lipids, they can target specific cell types, and unlike peptides their conjugation chemistry can be simplified by use of hybridisation or co-synthesis (Chu et al. 2006a). Their low molecular weights facilitate their penetration into tissues and cells. For pharmaceutical applications, aptamers require modification to provide resistance against nucleases and to prolong their lifetime in the bloodstream (Brody and Gold 2000). Aptamers bound to signal emitters, such as fluorochromes or radionuclides, label cancer cells selectively (Hicke et al. 2006; Chu et al. 2006a) and are capable of suppressing the proliferation of some cancer cells (Huang et al. 2008a). They have been targeted mainly to prostate cancers, but also to breast cancer, lung cancer, and lymphomas (Shangguan et al. 2006). Conjugated to small molecules such as siRNAs (Chu et al. 2006a), toxins (Chu et al. 2006b), or doxorubicin (Lupold et al. 2002), they are taken up specifically and mediate targeted destruction of the target cells. Conjugated to nanoparticles, their relatively weak binding can be compensated by attaching many aptamers to each nanoparticle (Huang et al. 2008b). Aptamer-nanoparticle conjugates have been extensively reviewed (Teply et al. 2006; Farokhzad et al. 2006b; Ellington et al. 2007). Conjugated to nanoparticles, they target cancer cells of different types, including prostate cancer (Lupold et al. 2002; Farokhzad et al. 2004, 2006a; Zhang et al. 2007; Wang et al. 2007) and breast cancer (Huang et al. 2008a). With specificity for integrins, they target tumour vasculature (Schiffelers et al. 2004), and targeted to VEGF, they strongly inhibit endothelial cell proliferation in vitro (Willis et al. 1998). They are ideal targeting groups for nanoparticles destined use in molecular imaging. Since they are very small, they require attachment to the nanoparticles via linkers sufficiently long to ensure that they are not sterically hindered from contacting their specific targets.

\section{Peptides}

Oligopeptides play multiple roles in nanomedicine. Some can serve as templates for nanoparticle formation, whereas others, especially homo-oligomers, are used as charged molecules for formation of nanoparticles (Kish et al. 2006). Small peptides are frequently the drug payloads incorporated into nanoparticles. Many others are used as targeting groups, including the RGD peptide, which binds specifically to integrin (Schiffelers et al. 2004), NC-1900, an active fragment analogue of arginine vasopressin (Xie et al.
2006), hexa-L-aspartic acid, which targets to bone (Hirabayashi and Fujisaki 2003), the TAT peptide for enhancement of cellular internalisation (Lutz et al. 2007) and signal peptides for nucleus and mitochondria (Hoshino et al. 2004). Oligopeptides share the advantages of aptamers when used as targeting groups.

\section{Lectins}

Lectin-conjugated nanoparticles have found uses in research applications (Paschkunova-Martic et al. 2005; Arangoa et al. 2000; Ezpeleta et al. 1999). Lectin-conjugates, ranging in size from $\sim 12 \mathrm{kDa}$ to more than $150 \mathrm{kDa}$, penetrate blood-tissue barriers with varying effectiveness. Their often exquisite specificity and binding affinity, rivalling those of the antibodies, can be used as blocking reagents but cannot activate the effector functions of the immune system. Unlike antibodies, their development must generally take place on a case-by-case system, inhibiting the establishment of a generally applicable corpus of techniques. Their major advantage over all other targeting systems, that they target oligosaccharide configurations, is not absolute: clinically relevant differential glycosylations can be recognised by antibodies (Pericleous et al. 2005). Many intercellular recognition functions are lectin-mediated (for example, the selectin recognition system, which initiates inflammation). As intercellular communication distortions become increasingly recognised as part of numerous pathophysiologies, therefore, lectins may have important roles to play in the future; it remains to be seen whether they will find a niche that cannot be occupied by antibodies.

\section{Specific ligands}

Molecules expressed specifically at the surfaces of relevant cells, such as endothelial cells or tumour cells, offer a wide choice of potential markers. Some of these underlie the greatest market successes in recent cancer therapeutics. Their use in molecular imaging is not so far developed, but could be of great importance in the future. A selection of such molecules is mentioned here; some of them highlight possible mechanisms for routing nanoparticles across tissue barriers and into cells. These molecules have been used to ferry drugs into tumours, but in each case, there is a potential for attaching these molecules to nanoparticles bearing signal-generating groups, thus adapting the molecules for use as diagnostic targeting groups in molecular imaging. The first class of molecules are the nutrient molecules. These require ferrying across barriers and therefore possess specific receptors, which initiate transport into and across barrier cells (such as endothelial cells) using endoytotic and transcytotic mechanisms. This allows a drug bound to the nutrient molecule to piggyback into and across the cell, so 
that the nutrient molecule serves as a "trojan horse". The first example is albumin, the major protein and transporter molecule of the blood, which binds as a ligand to specific receptors (Vogel et al. 2001) on the surfaces of endothelial cells and also of tumour cells (John et al. 2003; Schubert et al. 2001; Predescu et al. 2004; Minshall et al. 2003; Tuma and Hubbard 2003; Tiruppathi et al. 1997; Yumoto et al. 2006). These receptors facilitate passage of albumin out of the blood and into solid tumours and tumour cells. Drugs bound to albumin therefore piggyback across the endothelial cells via active transport (Chuang et al. 2002). The uptake receptors for albumin are expressed in increased amounts in tumours (Brown et al. 2001; Thomas et al. 2000; Watkins et al. 2005; Infante et al. 2007). Albu$\mathrm{min}$ is an excellent targeting ligand for these reasons and is now being attached to a variety of drugs to improve their bio-availability and bio-compatibility. The first example of this is nab-paclitaxel ("nanoparticle albumin bound-paclitaxel”) (Abraxan $\left.{ }^{\circledR}\right)$, which consists of a nanoparticle, approximately $150 \mathrm{~nm}$ diameter, with a core containing the taxane paclitaxel and the albumin surrounding it. The albumin targets the drug to the solid tumour, as demonstrated in clinical trials (Gradishar et al. 2006); the formulation was approved for clinical use by FDA in 2005. Albumin uptake and targeting involves mechanisms necessary for tumour cell nutrition; therefore, it is common to many types of tumour and is a strong candidate for molecular imaging detection of tumours. A similar example is the use of transferrin to target drugs to tumours via receptor-mediated mechanisms (Heidel et al. 2007; Iinuma et al. 2002), bypassing the P-glycoprotein (Schnyder et al. 2005). In addition to use of transferrin as ligand, the transferrin receptor is targeted by use of anti-transferrin antibodies. A third example is the use of the lipoprotein receptor to ferry drugs across the blood-brain barrier. (Low density) apolipoprotein receptors B,E (Weisgraber 1994) are common in the central nervous system (Pitas et al. 1987), and on endothelial apical cell surfaces (Meresse et al. 1989), where they mediate uptake of lipids into the central nervous tissue (Ribalta et al. 2003) by endocytosis and transcytosis (Vasile et al. 1983) and possibly participate in cell signalling mechanisms (Nimpf and Schneider 2000). They are therefore well suited for use in ferrying nanoparticles into the brain, using lipoproteins (Kreuter 2002; Michaelis et al. 2006) or mimetic molecules (Croy et al. 2004) as Trojan horses. Folate is a fourth example. Tumour cells frequently express high levels of folate receptor, which has been shown to facilitate entry of folate-conjugated toxins and prodrugs into the tumour cells. Folate has been used to target nanoparticles into tumours (Rossin et al. 2005; Gabizon et al. 2003; Shmeeda et al. 2006; Shiokawa et al. 2005). A final example is the mannose receptor; these are expressed exclusively on antigen-presented cells; mannose has been used to target nanoparticles to macrophages and dendritic cells (Hattori et al. 2006). A second class of specific molecules for targeting are the growth factor receptors, which are often expressed in especially high concentrations at the surfaces of tumour cells. One example is the family of transmembrane receptor tyrosine kinases, such as the receptor for epithelial growth factor (erbB/HER/EGF-R) (Lidke et al. 2004), and another is the family of receptors for the vascular endothelial growth factor (VEGF-R) (Willis et al. 1998). However, at present, the ligands EGF and VEGF are not are not utilised to target their receptors; instead, these receptors are targeted by use of specific antibodies. A third class of specific molecules for targeting are the cell surface adhesion molecules, which also are often expressed in especially high concentrations at the surfaces of tumour cells. EpCam (CD326), one of the first tumour-associated antigens identified (Baeuerle and Gires 2007), is overexpressed in a wide range of tumours including breast carcinomas (Osta et al. 2004), urothelial carcinomas (Brunner et al. 2008), pancreatic carcinomas (Fong et al. 2008), and hepatocellular carcinomas (Yamashita et al. 2007). This list represents only a small selection amongst the many lesionspecific ligand-receptor pairs that can be considered for use as targeting systems in diagnostic molecular imaging.

\section{The signalling groups}

The selection of signalling groups depends on the application for which the molecular imaging is planned. In some cases, damage to ionising radiation must be avoided; in other cases, it can be accepted. For some purposes, an inexpensive modality is appropriate; for other purposes, an expensive modality must be used. Financial and ethical considerations must be integrated with the technical considerations.

Strongly ionising signalling groups are acceptable in monitoring these therapies in which strong ionisation is part of the therapy itself (for example, in brachytherapy, in antibody-targeted and aptamer-targeted radionuclear therapies). PET imaging is therefore a staple of therapies in nuclear medicine. The scintigraphic imaging presently used to detect metastases in oncology is also being supplemented by scintigraphic molecular imaging. Ionising radiation is required for detailed imaging of calcified tissues; other possible applications are considered below.

Amongst the non-ionising signalling media, photons in the visible spectrum are the most easily generated and the least expensive. For surface and near-surface imaging, the near-infrared spectrum is ideal and is well represented by quantum dots and by organic fluorochromes. For studies involving small animals and tissue cultures in research, the entire visible spectrum and the near-infrared spectrum are used in combination with light microscopy of several various types, and with optical imaging by use of cameras. It is 
possible to attach antibodies of different specificities to different colours of quantum dots and thus to perform multispectral imaging, allowing tracking of several different antigens simultaneously. Unfortunately, quantum dots find only limited applications in patient care, because they contain semiconductor cores fabricated from highly toxic elements. They have been used to locate sentinel nodes in oncology. However, they are a varied group of nanoparticles typically based on toxic cores, which may be exposed by oxidative, photolytic, and mechanical instabilities (Hardman 2006; Chan et al. 2005). Their suitability as vehicles for targeted drug delivery is debatable, because any disruption of the outer shell (in which the drug must be loaded) may expose the toxic core. An alternative to quantum dots are the nanoclusters of silver and gold, which also have exciton properties and emit pure monochromatic light; the gold nanoclusters provide a non-toxic source of strong signalling for fluorescence microscopy and optical imaging.

The deep internal organs of large animals and humans can most expeditiously and inexpensively be imaged by use of ultrasound molecular imaging. MRI by use of USPIOs or SPIOs presently provides tracking of lymph nodes in oncology, and MRI by use of other nanoparticle contrast media is being developed for future use. The signalling groups available for MRI include not only gadolinium but also fluorine and europium.

Screening for latent illness is one of the future possibilities of molecular imaging. The nanoparticles required for this will be costly; so, such screening will only be financially viable for major killer diseases. The ethical, financial, and technical conundrums become most visible in this connection. The choice of imaging modality is here largely determined by expense and availability, which renders MRI an unlikely selection. PET is likewise hampered by the extensive infrastructure required and by the application of strongly ionising radiation. Ultrasound imaging is a likely candidate, with the proviso that the microbubbles must be shown to penetrate to biomarkers hidden deep within early lesions. For near-surface structures such as the peripheral arteries and veins, which are of considerable interest for screening for atherosclerosis, near-infrared optical imaging and photoacoustic imaging both provide strong candidates. Finally, direct X-ray imaging offers an inexpensive modality with minimal ionisation damage, justified if it is shown to detect early stages of major killer diseases and to impact morbidity or mortality rates. Screening applications of molecular imaging are at present hopes for the future and have not been realised in practise.

\section{The linkers}

The high affinity of the targeted nanoparticle for its target does not depend solely on the targeting group, but on the entire particle, including the linker and the linked particle. The targeting groups must retain or acquire their functional conformation (e.g. aptamers), and must present their binding site in an orientation, which allows binding and at a distance from the bulk of the particle so that steric hindrance does not prevent binding. These requirements for spatial positioning of each targeting group mandate selection of a linker of appropriate size, shape, and stiffness. In addition, the electronic configuration at the binding site (overall charge, charge distribution at the binding site) must facilitate binding, and this requires that the chemistry of the linker be chosen to configure charge accurately around the binding site. Selection of a suitable linker is an intricate and time-consuming task, even for attachment of a targeting group to a small molecule. It is a task likely to require yet more attention for the attachment of a targeting group to a nanoparticle, which is typically more than 10,000 times more massive than a small drug molecule. At present, many workers attach the targeting groups to nanoparticles by use of PEG as linker (Schiffelers et al. 2004), thus using the PEG both as linker and as an immune-evasion coating. Alternatively, avidin-biotin non-covalent linkages are employed (Schnyder et al. 2005; Wu et al. 2003; Chan et al. 2005), with their intrinsic advantage of modularity, allowing any biotinylated targeting group to be easily mounted on an avidin-bearing nanoparticle. Streptavidin, used for targeted delivery of therapeutics in whole animals (Zhang and Pardridge 2001; Schnyder et al. 2005), is a tetramer (Chu et al. 2006a), binding four biotins and thus allowing mixing of internalising and targeting moieties (Chu et al. 2006a; Ellington et al. 2007). Finally, there may be an important role in the future for use of nucleotide linkers to connect targeting groups with nanoparticles. Both DNA and RNA oligonucleotides are being actively studied as a means to build arrays of nanoparticles in materials and sensor sciences (Letsinger et al. 2001); these technologies can be applied by straight transfer to linking targeting groups to nanoparticles. Oligonucleotide linkages provide in principle the possibility of pre-programming functions into the linkage between targeting group and nanoparticle.

\section{Tissue barriers}

The shortest path to tissues in most internal organs is via the blood, generally after intravenous injection. This short path is nonetheless complex: the nanoparticles' target may lie behind several blood-tissue barriers, including endothelial cells, subendothelial basement membranes (spatial and charge filters), micrometres of extracellular matrix (also a filter) in which sheetlike fibroblast processes and collagen bundles form physical obstacles, and finally the subepithelial basement membrane (Fig. 6). These barriers are reduced in lesions, allowing wash-in of the nanoparticles, 


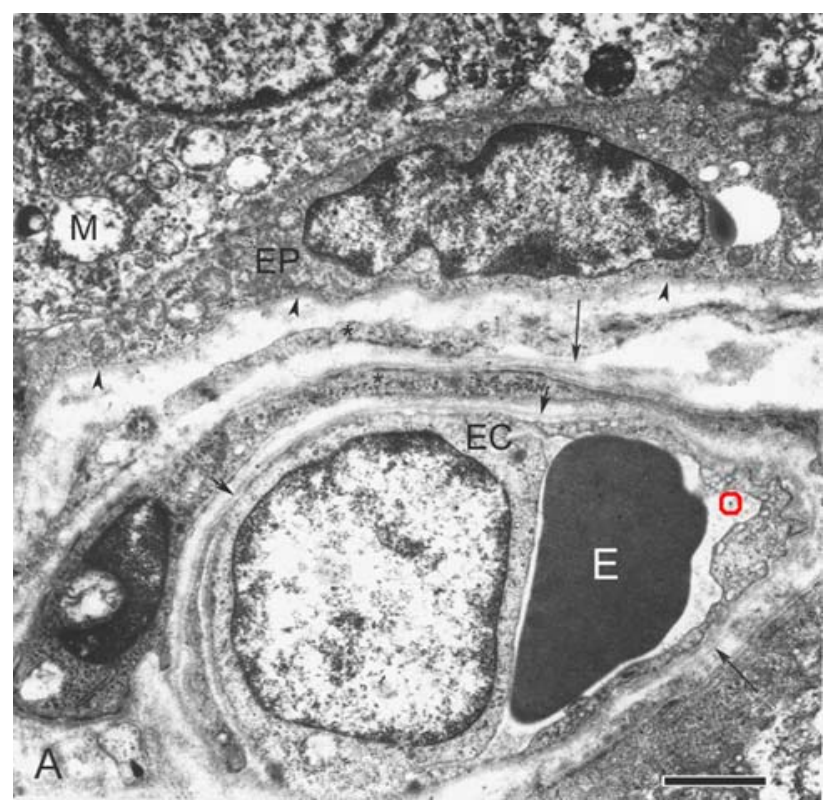

Fig. 6 Electron micrograph [reproduced from Wieser et al. (2004), with permission], showing the morphological barriers hindering a nanoparticle in the blood (inside red ring) from reaching its target in the cytoplasm of an epithelial cell. The prostate carcinoma tissue shown here has an area of the tumour in which the morphological relationships resemble those of non-cancerous tissue, and in which the system of barriers is essentially complete: this is a region of the tumour in which any cancer cells present will be difficult for targeted nanoparticles to access. The nanoparticle, in the capillary lumen, must cross the endothelial wall ( $E C$ endothelial cell), then the subendothelial basement membrane (short arrows), any fibroblast sheetlike processes (*) in close proximity to the blood vessel, extracellular matrix containing collagen fibres (long arrows), the subepithelial basement membrane (arrowheads) and finally cross the epithelial cell membrane to enter the cytoplasm of the epithelial cell (EP). The presence of caveolae in the wall of the endothelial cell (to the right side of the nanoparticle) already represents a partial failure of the barriers in this tissue. Calibration bar $1.0 \mu \mathrm{m}$

followed by accumulation of the nanoparticles in the lesion. Ideally, all the targeted nanoparticles will accumulate at the targets, but this $100 \%$ targeting efficiency is not reached for several reasons; some nanoparticles are sequestered into the reticulo-endothelial system and others into the liver. Furthermore, those nanoparticles, which remain in the blood, generate a background signal, which reduces the contrast available for detection of signal from the target sites. Reduction of the background signal can be achieved by PEGylation, reducing uptake into the reticulo-endothelial system. It can be achieved by shortening the halflife of the nanoparticles in the blood. The background signal can be reduced dramatically by arranging for signal generation to occur only when switched on at arrival in the target site: "molecular beacons" (Massoud and Gambhir 2003).

Viruses, natural nanoparticles, do overcome such barriers and reach multiply protected targets: the polio virus starts from the gut lumen to reach targets in the central nervous system. Viruses, however, bear enzymes to modify their environment, which until now has not been achieved with artificial nanoparticles.

\section{Toxicity and pharmacokinetics}

Nanoparticle interactions with living tissues bring novel risks. Nanoparticles have immense surface areas for chemical reaction: $1 \mathrm{~g}$ of $30 \mathrm{~nm}$ diameter nanoparticles contains a particle surface area $>200 \mathrm{~m}^{2}$, exceeding the combined surface areas of one hundred men (each with surface area $\sim 1.5 \mathrm{~m}^{2}$ ). Obvious risks are therefore potentiated (Brown et al. 2001; Donaldson et al. 2006; Oberdörster et al. 2005b). Some nanoparticles, such as quantum dots, are constructed from highly toxic materials and their dangers are evident. However, unexpected toxicities have been documented for materials, which are not normally considered toxic, such as silver, but which become toxic when presented in nanoparticle form. Furthermore, extensive epidemiological studies have shown that materials, which are toxic, such as particulate materials in industrial smokes and in smog (Brown et al. 2001; Clancy et al. 2002; Gilmour et al. 2004; Dailey et al. 2006; Lam et al. 2004; Medina et al. 2007; Pope 2001; Peters and Pope 2002; Salvi et al. 2000; Steerenberg et al. 1998; Yang et al. 1997), are decidedly more toxic if they are present as nanoparticles rather than as microparticles (Brook et al. 2004; Donaldson et al. 2005; Gilmour et al. 2004; Yamawaki and Iwai 2006). The use of (undeclared) nanoparticle therapeutics in medicine has so far not led to significant health risks. The FDA and the EMEA do not at present detect nanoparticle-specific risks. However, there are several grounds for caution. In principle, any active agents within the nanoparticle should be steered to the target site without adding risk. The ideal drug-bearing nanoparticle will release its drug only at the required site of action; it will release all its drug there at a specified rate, and the nanoparticle will then dissolve into entirely non-toxic components. The present state of the art does not attain these goals, and the nanoparticles release their loads too early and non-specifically, or have a pharmacokinetic of their own, which must be checked for toxicity. The multiple pharmacokinetic pathways characterising nanoparticles composed of several components must be checked, in particular ensuring that one type of clearance is not interfering with another. Some nanoparticle breakdown products, such as gadolinium chelates, have well-studied pharmacokinetics involving toxic risk to a very small number patients with kidney diseases (Broome et al. 2007; Kuo et al. 2007; Rofsky et al. 2008): this toxicity is not nanoparticle-specific, but nanoparticles containing these chelates may cause such toxicity if they are administered. Nanoparticles are as risky as their components, in addition to any further risks due to their nanoscale size. Concerning the 
nanoscale, there is as yet an unexplored question as to what interactions might occur between artifically introduced nanoparticles and the numerous natural nanoparticles, which are essential for the vital functions of cells and organs (Oberdörster et al. 2005a, b). Most of the intracellular machinery consists of nanoparticles (ribosomes, proteasomes, intracellular vesicles, ion channels, various membrane transporters, the nucleotides DNA and RNA in two of their three dimensions, the cytoskeletal fibres in two of their three dimensions, and many others); many extracellular components also have nano-dimensions. The potentially highly reactive nanoparticles may enter as yet unexplored interactions with biological nanoscale structures. There are then certain forms of toxicity that may be associated especially with targeted nanoparticles; for example, if an antibody as targeting group steers the particles into a healthy tissue, because that tissue presents epitopes cross-reacting with the target epitopes of the pathological tissues; the result of such cross-steering could be a heavy effective dose to a healthy tissue in addition to the therapeutic dose to the diseased tissue, and could thus cause particularly severe side-effects. In addition to this, it has been shown that effective targeting reduces, and ineffective targeting raises, exposure in the liver (Iinuma et al. 2002). In radionuclide-based imaging, there is in addition a need to reduce the radio dose to the kidney (Forster et al. 2006). The targeting group may also activate the immune response, as has been documented for some aptamers (Reynolds et al. 2006) and proteins (Heidel et al. 2007). The linker may also elicit an immune response, for example streptavidin (Breitz et al. 2000), though it is possible to minimise this (Meyer et al. 2001). In view of the nanostructure-specific potential toxicities and enhanced toxicities, it is necessary to develop specially adapted hierarchical standardised toxicity testing procedures for nanomedicine. Nanotoxicology is emerging as a new branch of toxicology, focussing on novel undesirable phenomena associated with nanoparticles (Donaldson et al. 2004; Service 2004; Seaton and Donaldson 2005). Tiered testing regimes taking account of properties specific to nanoparticles are being developed. These include testing and understanding potentially toxic effects of particles size (Jani et al. 1990), size distribution, agglomeration state, shape, crystal structure, e.g., single-wall carbon nanotubes induce pulmonary interstitial fibroses whereas carbon black (amorphous carbon nanostructures) do not (Kipen and Laskin 2005; Schvedova et al. 2003; Lam et al. 2004; Donaldson et al. 2006), chemical composition (Dailey et al. 2006), surface area, surface chemistry, surface charge, and porosity. Hierarchical toxicological testing protocols under development will assay these combined risks (Oberdörster et al. 2005b). In this way, the multidisciplinary nature of nanotoxicology reflects that of nanotechnology itself (Oberdörster et al. 2005a, b).
Perspectives

Nanomedicine applies the remarkable properties of nanosized materials to healthcare, increasing diagnostic sensitivity and specificity for specific disease-related processes and molecules. This includes remarkable enhancements in the clinical laboratory (e.g., Lee et al. 2007) and in histopathology (e.g., Xing et al. 2007); amongst this vast new field, this review has focussed on imaging in living organisms, which offers the potential to detect diseases at an early stage, gain new insights in the pathogenesis of certain diseases, monitor therapeutic response, and develop individualised therapies for certain diseases. Aims include identifying apparently healthy people hiding threatening lesions (Boisseau et al. 2006). In molecular imaging, localised clusters of cells bearing molecular insignia of disease are good targets, imaging with high contrast, because the surrounding tissue lacks such insignia. An early-stage tumour, prior to the angiogenic switch (Folkman 2001) and less than 2 mm diameter, contains more than two million cells, so is well within the detection and resolution capabilities of nanoparticle-based MRI. Nanoparticle-based molecular imaging therefore offers the potential of identifying malignancies at stages much earlier than those detectable today. Similar considerations apply to atherosclerotic lesions (Hellings et al. 2007). Any disease in which small disseminated lesions have diagnostic significance is a candidate for diagnostic molecular imaging; this includes infections, endometrioses, multiple sclerosis, and cancer (Weissleder and Pittet 2008). Diagnostic molecular imaging is a hot research field in which numerous workers are following different leads; so, a short review cannot do justice to the multiplicity of excellent reports; the field was reviewed frequently during the last 10 years (Massoud and Gambhir 2003; Moghimi et al. 2001; Jaffer and Weissleder 2005; Brindle 2003; Weissleder and Mahmood 2001; Wickline and Lanza 2003; Pomper 2005). Research highlights include imaging of angiogenesis with integrin $\alpha_{5} \beta_{3}$ as target or of thrombi with fibrin as target (Wickline and Lanza 2003), and of angiogenesis with matrix metalloproteases imaged by probes that can be activated (Massoud and Gambhir 2003). Tumour cell imaging was carried out in breast cancer by use of Her2/neu (Herceptin ${ }^{\circledR}$ ) by both photoacoustic imaging (Copland et al. 2004) and MRI (Lee et al. 2007). A major focus has been the imaging of gene expression (Massoud and Gambhir 2003; Weissleder and Mahmood 2001). Stem cell tracking has been found to succeed better by use of MPIOs than USPIOs or PIOs, as described earlier. Further aims include not just the diagnosis but also the staging of established disease, and provision of surrogates for drug testing. A long-term aim is to combine molecular imaging with therapy, with drug delivery: "theranostics" (Boisseau et al. 2006), as a major step towards personalised medicine. 
This review touched upon the fundamental issues, which unite histochemistry and molecular imaging, then moved on to consider novel aspects arising from the creation of what are in effect histochemical stains designed for use in clinical procedures to diagnose illnesses in patients. For the histochemist, much of the terrain is familiar, though the replacement of the microscope as imaging device requires an adjustment of thought. This is well worth while. In the newly emerging fields of molecular imaging diagnostics and theranostics, the histologist has considerable expertise to offer, without which much will need to be developed by trial and error, which could be rationally designed much more quickly and effectively if the histochemist plays his role. This impinges on the design of the new nanoparticulate contrast agents. Indeed, nanomedicine is essentially multidisciplinary. A wide range of chemical and physicochemical competencies is required to design, synthesise, and analyse nanoparticles. The identification of targets in numerous diseases, expression of those targets, screening for specific targeting groups, and validating those selected requires skills in genetics, bio-informatics, chemistry, molecular and cell biology, screening procedures, and pathology. Clinical aspects require input from radiologists, nuclear physicians, oncologists, pathologists, as well as anatomists, histologists, and physiologists. Pharmacological and logistical aspects require input from the pharmaceutical sciences and industries. Selection of diseases to address requires guidance from health-insurance experts, actuaries, and health-care managers. Last but not least, important ethico-legal issues require consideration. It is evident that no one person can master this gamut of trades, but a significant minority of those involved in DMI must speak an adequate range of the specialist languages involved. At this interface between medicine, biology, and materials science, those who will make it happen require training considerably broader-based than what traditional programs foresee.

This review closes with a glance at the "industrial" issues of logistics and regulation. As molecular imaging moves forward into clinical applications, the numerous proofs of principle that have been achieved must be converted into pharmaceutical realities, bringing three types of challenge unfamiliar in the laboratory setting. Firstly, nanoparticle synthesis must be upscaled, standardised, and streamlined. Nanomedicine in Europe will require annual production of tons of nanoparticles. Consider a person containing $3 \mathrm{ml}$ target tissue, then if MRI requires $1 \mathrm{mg} / \mathrm{ml}$ of gadolinium chelate in the target(s), and this in the form of 4,000 gadolinium ions per $30 \mathrm{~nm}$ nanoparticle, then about $1 \mathrm{~g}$ of nanoparticles with $10 \%$ targeting efficiency will be required for imaging. Thus, 400 million Europeans screened annually would require $\sim 400$ tons. Upscaleable syntheses are obviously essential. Physicochemical methods used to synthesise nanoparticles, such as emulsification or co-acervation, involve numerous parameters difficult to regulate, including local reagent concentrations, local $\mathrm{pH}$ and temperature, and flow rates. Intrinsic to such syntheses are significant variations amongst the end-products; we and others (Vogel et al. 2002) found significant variability in nanoparticle size dispersity and gadolinium loading ratios. The twin aims of upscaling and nanoparticle standardisation represent significant challenges to chemistry in bringing nanomedicine to full fruition. Streamlining is required primarily to trim the number of targeting groups per particle; for some nanoparticles, the cost of targeting is hundred-fold more expensive than the nanoparticle itself.

Following successful upscaling, there will be regulatory hurdles facing nanoparticles for molecular imaging in clinical application. As evidence for the proximity of clinical applications, the FDA has established a Nanoparticle Task Force to examine the regulatory issues associated with nanomedicine (http://www.fda.gov/nanotechnology/taskforce/report2007.html). The use of nanoparticles for therapeutic applications is further advanced than for diagnostics, and the FDA has slightly eased the regulatory background for diagnostics. Different forms of iron oxide nanoparticles for passive targeting are available for clinical use (Resovist, Feridex/Endorem, Gastromark/Lumirem). Several groups have Phase I/II trials of lymph node diagnostics to stage carcinomas, including breast, prostate, kidney, testis, bladder, and penis. It seems likely that the pre-operative sentinel node test will in future be carried out by use of non-ionising imaging, probably optical imaging. There is significant funding for translational diagnostic molecular imaging research in the USA, China, Japan, and the European Union. A cursory search of the Internet reveals more than 20 Molecular Imaging Facilities at universities and research institutes across the USA, and at least one or two in each of the developed countries; frequently, an industry partner is closely associated with such facilities, notably Siemens, General Electric, and Philips, and there are active research programs at Bracco and Guerbet, the major manufacturers of contrast agents.

The safety aspects of molecular imaging have been in the public eye for some time, and although there has been no cause for anxiety until now, the perception of nanotechnology is likely to be ambivalent for some time to come. The continued focus on this aspect is reflected not only in attention by the mass media but also by requirements placed on project leaders to demonstrate that they have considered any potential toxicities of the agents they are developing. So long as this alert environment is maintained it is likely that any untoward reactions towards diagnostic molecular imaging reagents will be detected and reported with minimal delay. 


\section{Conclusions}

Molecular imaging by use of nanoparticles, and its major daughter, diagnostic molecular imaging, is exploring a wide range of different nanoparticle formulations and applications. When high-quality biomarkers for early disease become available, the nanoparticles required for realisation of diagnostic molecular imaging on a wide front will be available. The present need is to develop cost-efficient nanoparticles with acceptable targeting efficiencies, favourable pharmacokinetics, and a good safety profile. The final point to consider is the question of realistic timeframes. The challenges in developing nanoparticles for molecular imaging will not be overcome within short timelines. The question of nanoparticle aggregation consequent to storage and reconstitution in the clinical setting requires to be addressed for multitasking nanoparticles. The convincing demonstration of non-toxicity in long-term applications and in the long-term after short-term applications will require periods of years subsequent to successful clinical trials. Unfamiliar types of risk must be identified and dealt with (for example, problems with false targeting). There are both legal and financial aspects to face before taking nanoparticulate agents to market, and in the marketplace these agents will be in competition with alternative technologies aimed at solving the same problems. Under these circumstances, the development of nanoparticles for clinical applications must be viewed as a matter for the long haul, with timelines counted in 5-year intervals. It would be surprising to see clinical applications before 2015, though this wait will be well worthwhile; histologists by proffering their skills can help to make this wait shorter.

Acknowledgments We are grateful to a large number of friends and colleagues who have contributed directly and indirectly to the material presented in this review. We especially thank the following for their significant input: Ruth Debbage, Christian Kremser, Heribert Talasz, Hans Grunicke, and Bernhard Keppler. We are grateful for efficient and cheerful constant assistance from Evelyn Neuhauser and Nicole Klammsteiner. Our work has been generously supported by a series of grants from the Austrian National Bank Jubilee Fund, over several years. We are also supported by the Austrian Nano-Initiative as part of the Nanohealth project, now in its fourth year.

\section{References}

Adler A, Forster N, Homann M, Göringer HU (2008) Post-SELEX chemical optimization of a trypanosome-specific RNA aptamer. Comb Chem High Throughput Screen 11:16-23

Agnihotri SA, Mallikarjuna NN, Aminabhavi TM (2004) Recent advances on chitosan-based micro- and nanoparticles in drug delivery. J Control Release 100:5-28

Alivisatos P (2004) The use of nanocrystals in biological detection. Nat Biotechnol 22:47-52

Allen MA, Leipold LO, Bulte JWM, Basu G, Zywicke HA, Frank JA, Young M, Douglas T (2005) Paramagnetic viral nanoparticles as potential high-relaxivity MRI contrast agents. Magn Reson Med 54:807-812

Arangoa MA, Ponchel G, Orecchioni AM, Renedo MJ, Duchêne D, Irache JM (2000) Bioadhesive potential of gliadin nanoparticulate systems. Eur J Pharm Sci 11:333-341

Artemov D, Mori N, Ravi R, Bhujwalla ZM (2003) Magnetic resonance molecular imaging of the HER-2/neu Receptor. Cancer Res 63:2723-2727

Baeuerle PA, Gires O (2007) EpCAM (CD326) finding its role in cancer. Br J Cancer 96:417-423

Bakalova R, Zhelev Z, Aoki I, Kanno I (2007) Designing quantum-dot probes. Nat Photonics 1:487-489

Balthasar S, Michaelis K, Dinauer N, von Briesen H, Kreuter J, Langer K (2005) Preparation and characterisation of antibody modified gelatin nanoparticles as drug carrier system for uptake in lymphocytes. Biomaterials 26:2723-2732

Benderbous S, Corot C, Jacobs P, Bonnemain B (1996) Superparamagnetic agents: physicochemical characteristics and preclinical imaging evaluation. Acad Radiol 3(Suppl 2):S292-S294

Benedum J, Meusch M (1999) Robert Feulgen (1884-1955)—some biographical thoughts. Histochem Cell Biol 111:337-343

Bhujwalla ZM, Artemov D, Natarajan K, Solaiyappan M, Kollars P, Kristjansen PEG (2003) Reduction of vascular and permeable regions in solid tumors detected by macromolecular contrast magnetic resonance imaging after treatment with antiangiogenic agent TNP-470. Clin Cancer Res 9:355-362

Blank M, Weinschenk T, Priemer M, Schluesener H (2001) Systematic evolution of a DNA aptamer binding to rat brain tumor microvessels. Selective targeting of endothelial regulatory protein pigpen. J Biol Chem 276:16464-16468

Boisseau P, Kiparissides C, Pavesio A, Saxl O, Ambrosio L, Benninghofen A, Bigay C-N, Borros S, Briel A, Bruce D, Chabbal J, Charbit F, Coche T, Deacon J, Debbage P, Eaton M, Fuchs H, Fuhr G, Goossens J, Guenther R, Hawlina M, Hofmeister A, Kasemo B, Kirkpatrick J, Kuhn MH, Marche P, Meisel HJ, Mestais C, Moore R, Ogorevc B, Peponnet C, Pieber T, Pirovano D, Puget P, Reinmann M, Riese J, Rodriguez JR, Samitier J, Scherfler H, Schild C, Schmidt S, Schreder S, Souquet J, Subramaniam V, Tavitian B, Venturini P, Vericat JA, von Bally G, Weltring K-M, Williams D, Zivin M (2006) European technology platform on nanomedicine: nanotechnology for health-strategic research agenda. European Commission, Office for Official Publications of the European Communities, Luxembourg, 39 pp. ISBN 92-7902203-2

Bosi S, Da Ros T, Spalluto G, Prato G (2003) Fullerene derivatives: an attractive tool for biological applications. Eur J Med Chem 38:913-923

Boulianne GL, Hozumi N, Schulman MJ (1984) Production of functional chimaeric mouse/human antibody region domains. Nature 312:643-646

Breitz HB, Weiden PL, Beaumier PL, Axworthy DB, Seiler C, Su FM, Graves S, Bryan K, Reno JM (2000) Clinical optimization of pretargeted radioimmunotherapy with antibody-streptavidin conjugate and ${ }^{90}$ Y-DOTA-biotin. J Nucl Med 41:131-140

Brindle KM (2003) Molecular imaging using magnetic resonance: new tools for the development of tumour therapy. $\mathrm{Br} \mathrm{J}$ Radiol 76:S111-S117

Brody EN, Gold L (2000) Aptamers as therapeutic and diagnostic agents. J Biotechnol 74:5-13

Brook RD, Franklin B, Cascio W, Hong Y, Howard G, Lipsett M, Luepker R, Mittleman M, Samet J, Smith SC Jr, Tager I (2004) Air pollution and cardiovascular disease: a statement for healthcare professionals from the expert panel on population and prevention science of the American heart association. Circulation 109:2655-2671

Broome DR, Girguis MS, Baron PW, Cottrell AC, Kjellin I, Kirk GA (2007) Gadodiamide-associated nephorgenic systemic fibrosis: 
why radiologists should be concerned. Am J Roentgenol 188:586-592

Brown DM, Wilson MR, MacNee W, Stone V, Donaldson K (2001) Size-dependent proinflammatory effects of ultrafine polystyrene particles: a role for surface area and oxidative stress in the enhanced activity of ultrafines. Toxicol Appl Pharmacol 175:191199

Bruchez M Jr, Moronne M, Gin P, Weiss S, Alivisatos AP (1998) Semiconductor nanocrystals as fluorescent biological labels. Science 281:2013-2016

Bruggemann M, Neuberger MS (1996) Strategies for expressing human antibody repertoires in transgenic mice. Immunol Today 17:391-397

Brunner A, Prelog M, Verdorfer I, Tzankov A, Mikuz G, Ensinger C (2008) EpCAM is predominantly expressed in high grade and advanced stage urothelial carcinoma of the bladder. J Clin Pathol 61:307-310

Bulte JWM, Douglas T, Witwer B, Zhang SC, Strable E, Lewis BK, Zywicke H, Miller B, van Gelderen P, Moskowitz BM, Duncan ID, Frank JA (2001) Magnetodendrimers allow endosomal magnetic labeling and in vivo tracking of stem cells. Nat Biotechnol 19:1141-1147

Cai XH, Garen A (1995) Anti-melanoma antibodies from melanoma patients immunized with genetically-modified autologous tumour-cells - selection of specific antibodies from single-chain fv fusion phage libraries. Proc Natl Acad Sci USA 92:6537-6541

Callaghan PT (1991) Principles of nuclear magnetic resonance microscopy. Oxford University Press, New York

Carter P, Presta L, Gorman CM, Ridgway JB, Henner D, Wong WL, Rowland AM, Kotts C, Carver ME, Shepard HM (1992) Humanization of an Anti-p185HER2 antibody for human cancer therapy. Proc Natl Acad Sci USA 89:4285-4289

Cerchia L, Ducongé F, Pestourie C, Boulay J, Aissouni Y, Gombert K, Tavitian B, de Franciscis V, Libri D (2005) Neutralizing aptamers from whole-cell SELEX inhibit the RET receptor tyrosine kinase. PLoS Biol 3:e123

Chan WCW, Nie S (1998) Quantum dot bioconjugates for ultrasensitive nonisotopic detection. Science 281:2016-2018

Chan P, Yuen T, Ruf F, Gonzalez-Maeso J, Sealfon SC (2005) Method for multiplex cellular detection of mRNAs using quantum dot fluorescent in situ hybridization. Nucleic Acids Res 33:e161

Chen X, Hou Y, Tohme M, Park R, Khankaldyyan V, Gonzales-Gomez I, Bading JR, Laug WE, Conti PS (2004a) Pegylated ArgGly-Asp peptide: $\mathrm{Cu}-64$ labeling and PET imaging of brain tumor alpha(v)beta(3)-integrin expression. J Nucl Med 45:1776-1783

Chen X, Park R, Hou Y, Tohme M, Shahinian AH, Bading JR, Conti PS (2004b) MicroPET and autoradiographic imaging of GRP receptor expression with $\mathrm{Cu}$-64-DOTA-Lys(3) bombesin in human prostate adenocarcinoma xenografts. J Nucl Med 45:13901397

Chen J, Wiley B, Li Z-Y, Campbell D, Saeki F, Cang H, Au L, Lee J, Li X, Xia Y (2005) Gold nanocages: engineering their structure for biomedical applications. Adv Mater 17:2255-2261

Chester KA, Begent RH, Robson L, Keep P, Pedley RB, Boden JA, Boxer G, Green A, Winter G, Cochet O, Hawkins RE (1994) Phage libraries for the generation of clinically useful antibodies. Lancet 343:455-456

Chotia C, Lesk AM, Tramontano A, Levitt M, Smith-Gill SJ, Air G, Sheriff S, Padlan EA, Davies D, Tulip WR, Colman PM, Spinelli S, Alzari PM, Poljak RJ (1989) Conformations of immunoglobulin hypervariable regions. Nature 342:877-883

Chu TC, Twu KY, Ellington AD, Levy M (2006a) Aptamer mediated siRNA delivery. Nucleic Acids Res 34(10):e73-e73

Chu TC, Marks JWIII, Lavery LA, Faulkner S, Rosenblum MG, Ellington AD, Levy M (2006b) Aptamer: toxin conjugates that specifically target prostate tumor cells. Cancer Res 66:5989-5992
Chuang VT, Kragh-Hansen U, Otagiri M (2002) Pharmaceutical strategies utilizing recombinant human serum albumin. Pharm Res 19:569-577

Clancy L, Goodman P, Sinclair H, Dockery DW (2002) Effect of airpollution control on death rates in Dublin, Ireland: an intervention study. Lancet 360:1210-1214

Colcher D, Pavlinkova G, Beresford G, Booth BJ, Choudhury A, Batra SK (1998) Pharmacokinetics and biodistribution of genetically engineered antibodies. Q J Nucl Med 42:225-241

Coons AH (1961) The Beginnings of Immunofluorescence. J Immunol 87:499-503

Copland JA, Eghtedari M, Popov VL, Kotov N, Mamedova N, Motamedi M, Oraevsky AA (2004) Bioconjugated gold nanoparticles as a molecular based contrast agent: implications for imaging of deep tumors using optoacoustic tomography. Mol Imaging Biol 6:341-349

Croy JE, Brandon T, Komives EA (2004) Two apolipoprotein E mimetic peptides, $\operatorname{ApoE}(130-149)$ and $\operatorname{ApoE}(141-155) 2$, bind to LRP1. Biochemistry 43:7328-7335

Cunningham CH, Arai T, Yang PC, McConnell MV, Pauly JM, Conolly SM (2005) Positive contrast magnetic resonance imaging of cells labeled with magnetic nanoparticles. Magn Reson Med 53:999-1005

Dailey LA, Jekel N, Fink L, Gessler T, Schmehl T, Wittmar M, Kissel $\mathrm{T}$, Seeger W (2006) Investigation of the proinflammatory potential of bio-degradable nanoparticle drug delivery systems in the lung. Toxicol Appl Pharmacol 215:100-108

D'Amato G (2003) Therapy of allergic bronchial asthma with omalizumab-an anti-IgE monoclonal antibody. Expert Opin Biol Ther 3:371-376

Daniels DA, Chen H, Hicke BJ, Swiderek KM, Gold L (2003) A tenascin-C aptamer identified by tumor cell SELEX: systematic evolution of ligands by exponential enrichment. Proc Natl Acad Sci USA 100:15416-15421

de Herder WW, Kwekkeboom DJ, Valkema R, Feelders RA, van Aken MO, Lamberts SW, van der Lely AJ, Krenning EP (2005) Neuroendocrine tumors and somatostatin: imaging techniques. J Endocrinol Invest 28:132-136

Dhaneshwar SS, Kandpal M, Gairola N, Kadam SS (2006) Dextran: a promising macromolecular drug carrier. Indian $\mathrm{J}$ Pharm Sci 68:705-714

Dodd SJ, Williams M, Suhan JP, Williams DS, Koretsky AP, Ho C (1999) Detection of single mammalian cells by high-resolution magnetic resonance imaging. Biophys J 76:103-109

Donaldson K, Stone V, Tran CL, Kreyling W, Borm PJA (2004) Nanotoxicology. Occup Environ Med 61:727-728

Donaldson K, Tran L, Jimenez L, Duffin R, Newby D, Mills N, MacNee W, Stone V (2005) Combustion-derived nanoparticles: a review of their toxicology following inhalation exposure. Part Fibre Toxicol 2:10

Donaldson K, Aitken R, Tran L, Stone V, Duffin R, Forrest G, Alexander A (2006) Carbon nanotubes: a review of their properties in relation to pulmonary toxicology and workplace safety. Toxicol Sci 92:5-22

Duncan R (2005) $N$-(2-hydroxypropyl)methacrylamide copolymer conjugates. In: Kwon GS (ed) Polymeric drug delivery systems. Marcel Dekker, New York, pp 1-92

Drummond DC, Meyer O, Hong K, Kirpotin DB, Papahadjopoulos D (1999) Optimizing liposomes for delivery of chemotherapeutic agents to solid tumors. Pharm Rev 51:691-743

Ehrlich P (1900) On immunity with special reference to cell life. Proc R Soc Lond 66:424

Elghanian R, Storhoff JJ, Mucic RC, Letsinger RL, Mirkin CA (1997) Selective colorometric detection of polynucleotides based on the distance-dependent optical properties of gold nanoparticles. Science 277:1078-1081 
Elke M (1995) The centenary of W. C. Roentgen's discovery: a look at developments in science, clinical radiologic practice and environmental problems. Cell Mol Life Sci 51:637-639

Ellington AD, Szostak JW (1990) In vitro selection of RNA molecules that bind specific ligands. Nature 346:818-822

Ellington AD, Ebright J, Chu T, Levy M (2007) Using aptamers for cell-specific labeling and delivery. In: American Association for Cancer Research education book, American Association for Cancer Research, Philadelphia, pp 51-55

Engberink RDO, van der Pol SMA, Döpp ED, de Vries HE, Blezer ELA (2007) Comparison of SPIO and USPIO for in vitro labeling of human monocytes: MR detection and cell function. Radiology 243:467-474

Ezpeleta I, Arango MA, Irache JM, Stainmesse S, Chabenat C, Popineau Y, Orecchioni A-M (1999) Preparation of Ulex europaeus lectin-gliadin nanoparticle conjugtaes and their interaction with gastrointestinal mucus. Int J Pharm 191:25-32

Farokhzad OC, Jon S, Khademhosseini A, Tran T-N, LaVan DA, Langer RL (2004) Nanoparticle-aptamer bioconjugates. A new approach for targeting prostate cancer cells. Cancer Res 64:76687672

Farokhzad OC, Cheng J, Teply BA, Sherifi I, Jon S, Kantoff PW, Richie JP, Langer R (2006a) Targeted nanoparticle-aptamer bioconjugates for cancer chemotherapy in vivo. Proc Natl Acad Sci USA 103:6315-6320

Farokhzad OC, Karp JM, Langer R (2006b) Nanoparticle-aptamer bioconjugates for cancer targeting. Expert Opin Drug Deliv $3: 311-324$

Fatouros PP, Corwin FD, Chen Z-J, Broaddus WC, Tatum JL, Kettenmann B, Ge Z, Gibson HW, Russ JL, Leonard AP, Duchamp JC, Dorn HC (2006) In vitro and in vivo imaging studies of a new endohedral metallofullerene nanoparticle. Radiology 240:756-764

Feld M, De Roo M (2003) History of nuclear medicine in Europe. In: Schicha H, Bergdolt K, Ell PJ (eds) (trans: Patton DD). Schattauer, New York, 166 pp

Flenniken ML, Willits DA, Harmsen AL, Liepold LO, Harmsen AG, Young MJ, Douglas T (2006) Melanoma and lymphocyte cellspecific targeting incorporated into a heat shock protein cage architecture. Chem Biol 13:161-170

Folkman J (2001) Can mosaic tumor vessels facilitate molecular diagnosis of cancer? Proc Natl Acad Sci USA 98:398-400

Fong D, Steurer M, Obrist P, Barbieri V, Margreiter R, Amberger A, Laimer K, Gastl G, Tzankov A, Spizzo G (2008) Ep-CAM expression in pancreatic and ampullary carcinomas: frequency and prognostic relevance. J Clin Pathol 61:31-35

Forster GJ, Santos EB, Smith-Jones PM, Zanzonico P, Larson SM (2006) Pretargeted radioimmunotherapy with a single-chain antibody/streptavidin construct and radiolabeled DOTA-biotin: strategies for reduction of the renal dose. J Nucl Med 47:140-149

Foster-Gareau P, Heyn C, Alejski A, Rutt BK (2003) Imaging single mammalian cells with a $1.5 \mathrm{~T}$ clinical MRI scanner. Magn Reson Med 49:968-971

Frangioni JV, Hajjar RJ (2004) In vivo tracking of stem cells for clinical trials in cardiovascular disease. Circulation 110:33783383

Frey A, Neutra MR, Robey FA (1997) Peptomer aluminum oxide nanoparticle conjugates as systemic and mucosal vaccine candidates: synthesis and characterization of a conjugate derived from the C4 domain of HIV-1MN gp120. Bioconjug Chem 8:424-433

Frey A, Mantis N, Kozlowski PA, Quayle AJ, Bajardi A, Perdomo JJ, Robey FA, Neutra MR (1998) Immunization of mice with peptomers covalently coupled to aluminum oxide nanoparticles. Vaccine 17:3007-3019

Gabizon A, Horowitz AT, Goren D, Tzemach D, Shmeeda H, Zalipsky S (2003) In vivo fate of folate-targeted polyethylene-glycol liposomes in tumor-bearing mice. Clin Cancer Res 9:6551-6559
Gao J, Hillebrenner HL (2008) Nanotubular probes as ultrasensitive MR contrast agent. US Patent Application 20,080,124,281

Gao XH, Cui YY, Levenson RM, Chung LWK, Nie SM (2004) In vivo cancer targeting and imaging with semiconductor quantum dots. Nat Biotechnol 22:969-976

Gao X, Yang L, Petros JA, Marshall FF, Simons JW, Nie S (2005) In vivo molecular and cellular imaging with quantum dots. Curr Opin Biotechnol 16:63-72

Gavilondo JV, Larrick JW (2000) Antibody engineering at the millennium. Biotechniques 29:128-146

Gilmour PS, Ziesenis A, Morrison ER, Vickers MA, Drost EM, Ford I, Karg E, Mossa C, Schroeppel A, Ferron GA, Heyder J, Greaves M, MacNee W, Donaldson K (2004) Pulmonary and system effects of short-term inhalation exposure to ultrafine carbon black particles. Toxicol Appl Pharmacol 195:35-44

Gradishar W, Krasnojon D, Cheporov S, Makhson A, Manikhas G, Clawson A, Hawkins MJ (2006) A randomized phase 2 trial of qw or q3w ABI-007 (ABX) vs q3w solvent-based docetaxel (TXT) as first-line therapy in metastatic breast cancer (MBC). Presented at 29th Annual San Antonio Breast Cancer Symposium, San Antonio, December 14-17, 2006, Texas, Abstract 46

Haes AJ, Van Duyne RP (2002) A nanoscale optical biosensor: sensitivity and selectivity of an approach based on the localized surface plasmon resonance spectroscopy of triangular silver nanoparticles. J Am Chem Soc 124:10596-10604

Hardman R (2006) A toxicologic review of quantum dots: toxicity depends on physicochemical and environmental factors. Environ Health Perspect 114:165-172

Hattori Y, Kawakami S, Nakamura K, Yamashita F, Hashida M (2006) Efficient gene transfer into macrophages and dendritic cells by in vivo gene delivery with mannosylated lipoplex via the intraperitoneal route. J Pharm Exp Ther 318:828-834

Heidel JD, Yu Z, Liu JYC, Rele SM, Liang Y, Zeidan RK, Kornbrust DJ, Davis ME (2007) Administration in non-human primates of escalating intravenous doses of targeted nanoparticles containing ribonucleotide reductase subunit M2 siRNA. Proc Natl Acad Sci USA 104:5715-5721

Hellings WE, Peeters W, Moll F, Pasterkamp G (2007) From vulnerable plaque to vulnerable patient: the search for biomarkers of plaque destabilization. Trends Cardiovasc Med 17:162-171

Heyn C, Ronald JA, Mackenzie LT, MacDonald IC, Chambers AR, Rutt BK, Foster PJ (2006) In vivo magnetic resonance imaging of single cells in mouse brain with optical validation. Magn Reson Med 55:23-29

Hicke BJ, Stephens AW, Gould T, Chang YF, Lynott CK, Heil J, Borkowski S, Hilger CS, Cook G, Warren S, Schmidt PG (2006) Tumor targeting by an aptamer. J Nucl Med 47:668-678

Hinds KA, Hill JM, Shapiro EM, Laukkanen MO, Silva AC, Combs CA, Varney TR, Balaban RS, Koretsky AP, Dunbar CE (2003) Highly efficient endosomal labeling of progenitor and stem cells with large magnetic particles allows magnetic resonance imaging of single cells. Blood 102:867-872

Hirabayashi H, Fujisaki J (2003) Bone specific drug delivery systems: approaches via chemical modification of bone-seeking agents. Clin Pharmacokinet 42:1319-1330

Hoehn M, Kustermann E, Blunk J, Wiedermann D, Trapp T, Wecker S, Focking M, Arnold H, Hescheler J, Fleischmann BK, Schwindt W, Buhrle C (2002) Monitoring of implanted stem cell migration in vivo: a highly resolved in vivo magnetic resonance imaging investigation of experimental stroke in rat. Proc Natl Acad Sci USA 99:16267-16272

Hofheinz RD, al-Batran SE, Hartmann F, Hartung G, Jäger D, Renner C, Tanswell P, Kunz U, Amelsberg A, Kuthan H, Stehle G (2003) Stromal antigen targeting by a humanised monoclonal antibody: an early phase II trial of sibrotuzumab in patients with metastatic colorectal cancer. Onkologie 26:44-48 
Homann M, Goringer HU (1999) Combinatorial selection of high affinity RNA ligands to live African trypanosomes. Nucleic Acids Res 27:2006-2014

Hoshino A, Fujioka K, Oku T, Nakamura S, Suga M, Yamaguchi Y, Suzuki K, Yasuhara M, Yamamoto K (2004) Quantum dots targeted to the assigned organelle in living cells. Microbiol Immunol 48:985-994

Huang JZ, Frischer JS, New T, Kim ES, Serur A, Lee A, Kadenhe-Chiwishe A, Pollyea DA, Yokoi A, Holash J, Yancopoulos GD, Kandel JJ, Yamashiro DJ (2004) TNP-470 promotes initial vascular sprouting in xenograft tumors. Mol Cancer Ther 3:335-343

Huang YF, Lin YW, Lin Z-H, Chang HT (2008a) Aptamer-modified gold nanoparticles for targeting breast cancer cells through light scattering. J Nanoparticle Res. doi:10.1007/s11051-008-9424-x

Huang YF, Chang HT, Tan W (2008b) Cancer cell targeting using multiple aptamers conjugated on nanorods. Anal Chem 80:567-572

Hudson PJ, Souriau C (2003) Engineered antibodies. Nat Med 9:129134

Hung CT, McLeod AD, Gupta PK (1990) Formulation and characterization of magnetic polyglutaraldehyde nanoparticles as carriers for poly-L-lysine-methotrexate. Drug Dev Ind Pharm 16:509-521

Iinuma H, Maruyama K, Okinaga K, Sasaki K, Sekine T, Ishida O, Ogiwara N, Johkura K, Yonemura Y (2002) Intracellular targeting therapy of cisplatin-encapsulated transferrin-polyethylene glycol liposome on peritoneal dissemination of gastric cancer. Int J Cancer 99:130-137

Infante JR, Matsubayashi H, Sato N, Tonascia J, Klein AP, Riall TA, Yeo C, Iacobuzio-Donahue C, Goggins M (2007) Peritumoral fibroblast SPARC expression and patient outcome with resectable pancreatic adenocarcinoma. J Clin Oncol 25:319-325

Inoue K, Chikazawa M, Fukata S, Yoshikawa C, Shuin T (2003) Docetaxel enhances the therapeutic effect of the angiogenesis inhibitor TNP-470 (AGM-1470) in metastatic human transitional cell carcinoma. Clin Cancer Res 9:886-899

Isaacs JD (1990) The antiglobulin response to therapeutic antibodies. Semin Immunol 2:449-456

Jaffer FA, Weissleder R (2005) Molecular imaging in the clinical arena. JAMA 293:855-862

Jani P, Halbert GW, Langridge J, Florence AT (1990) Nanoparticle uptake by the rat gastrointestinal mucosa: quantitation and particle size dependency. J Pharm Pharmacol 42:821-826

Jeon SH, Kayhan B, Ben-Yedidia T, Arnon R (2004) A DNA aptamer prevents influenza infection by blocking the receptor binding region of the viral hemagglutinin. J Biol Chem 279:48410-48419

Jin X, Xu M, Wang LV, Fang YR, Zanelli CI, Howard M (2005) Imaging of HIFU-induced lesions in soft biological tissue using thermoacoustic tomography. Med Phys 32:5-11

John TA, Vogel SM, Tiruppathi TC, Malik AB, Minshall RD (2003) Quantitative analysis of albumin uptake and transport in the rat microvessel endothelial monolayer. Am J Physiol Lung Cell Mol Physiol 284:L187-L196

Jung CW (1995) Surface properties of superparamagnetic iron oxide MR contrast agents: ferumoxides, ferumoxtran, ferumoxsil. Magn Reson Imaging 13:675-691

Kabat EA, Wu TT, Bilofsky H, Reid-Miller, Perry HM (1991) Sequences of proteins of immunological interest, NIH Publication No. 369-847. NIH, Bethesda. http://www.kabatdatabase.com/index.html

Karpas A, Dremucheva A, Czepulkowski BH (2001) A human myeloma cell line suitable for the generation of human monoclonal antibodies. Proc Natl Acad Sci USA 98:1799-1804

Keefe AD, Schaub RG (2008) Aptamers as candidate therapeutics for cardiovascular indications. Curr Opin Pharmacol 8:147-152

Kellermann SA, Green LL (2002) Antibody discovery: the use of transgenic mice to generate human monoclonal antibodies for therapeutics. Curr Opin Biotechnol 13:593-597
Kim S, Lim YT, Soltesz EG, De Grand AM, Lee J, Nakayama A, Parker JA, Mihaljevic T, Laurence RG, Dor DM, Cohn LH, Bawendi MG, Frangioni JV (2003) Near-infrared fluorescent type II quantum dots for sentinel lymph node mapping. Nat Biotechnol 22:93-97

Kipen HM, Laskin DL (2005) Smaller is not always better: nanotechnology yields nanotoxicology. Am J Physiol Lung Cell Mol Physiol 289:L696-L697

Kircher MF, Allport JR, Graves EE, Love V, Josephson L, Lichtman $\mathrm{AH}$, Weissleder R (2003) In vivo high resolution three-dimensional imaging of antigen-specific cytotoxic T-lymphocyte trafficking to tumors. Cancer Res 63:6838-6846

Kish PE, Tsume Y, Kijek P, Lanigan TM, Hilfinger JM, Roessler BJ (2006) Bile acid-oligopeptide conjugates interact with DNA and facilitate transfection. Mol Pharm 4:95-103

Kobayashi H, Kawamoto S, Brechbiel MW, Bernardo M, Sato N, Waldmann TA, Tagaya Y, Choyke PL (2005) Detection of lymph node involvement in hematologic malignancies using micromagnetic resonance lymphangiography with a gadolinum-labeled dendrimer nanoparticle. Neoplasia 7:984-991

Köhler G, Milstein C (1975) Continuous cultures of fused cells secreting antibody of predefined specificity. Nature 256:495-497

Kreuter J (2002) Transport of drugs across the blood-brain barrier by nanoparticles. Curr Med Chem Central Nervous Syst Agents 2:241-249

Kruger RA, Stantz KM, Kiser WL (2002) Thermoacoustic CT of the breast. Proc SPIE 4682:521-525

Kruger RA, Kiser WL, Reinecke DR, Kruger GA, Miller KD (2003) Thermoacoustic molecular imaging of small animals. Mol Imaging 2(2):113-123

Kuo PH, Kanal E, Abu-Alfa AK, Cowper SE (2007) Gadoliniumbased MR contrast agents and nephrogenic systemic fibrosis. Radiology 242:647-649

Lam C-W, James JT, McCluskey R, Hunter RL (2004) Pulmonary toxicity of single-wall carbon nanotubes in mice 7 and 90 days after intratracheal instillation. Toxicol Sci 77:126-134

Lanman J, Crum J, Deerinck T, Gaietta GM, Schneemann A, Sosinsky GE, Ellisman MH, Johnson JE (2008) Visualizing flock house virus infection in Drosophila cells with correlated fluorescence and electron microscopy. J Struct Biol 161(3):439-446

Lanza GM, Winter PM, Neubauer AM, Caruthers SD, Hockett FD, Wickline SA (2005) ${ }^{1} \mathrm{H} /{ }^{19} \mathrm{~F}$ magnetic resonance molecular imaging with perfluorocarbon nanoparticles. Curr Top Dev Biol 70:57-76

Laufer J, Elwell C, Delpy D, Beard P (2005) In vitro measurements of absolute blood oxygen saturation using pulsed near-infrared photoacoustic spectroscopy: accuracy and resolution. Phys Med Biol 50(18):4409-4428

Lauterbur PC (1973) Image formation by induced local interactions: examples employing nuclear magnetic resonance. Nature 242:190-191

Lee CC, MacKay JA, Fréchet JM, Szoka FC (2005) Designing dendrimers for biological applications. Nat Biotechnol 23:1517-1526

Lee JH, Huh YM, Jun YW, Seo JW, Jang JT, Song HT, Kim S, Cho EJ, Yoon HG, Suh JS, Cheon J (2007) Artificially engineered magnetic nanoparticles for ultra-sensitive molecular imaging. Nat Med 13:95-99

Lee J, Kim J, Park E, Jo S, Song R (2008) PEG-ylated cationic CdSe/ $\mathrm{ZnS}$ QDs as an efficient intracellular labeling agent. Phys Chem Chem Phys 10:1739-1742

Letsinger RL, Mirkin CA, Park SJ, Viswanadham G, Zhang L (2001) Poly(oligonucleotide) conjugates: applications in assembling nanoparticles and in detecting DNA sequences. Nucl Acids Res Suppl (1):1-2

Lewis JD, Destito G, Zijlstra A, Gonzalez MJ, Quigley JP, Manchester M, Stuhlmann H (2006) Viral nanoparticles as tools for intravital vascular imaging. Nat Med 12:354-360 
Lidke DS, Nagy P, Heintzmann R, Arndt-Jovin DJ, Post JN, Grecco HE, Jares-Erijman EA, Jovin TM (2004) Quantum dot ligands provide new insights into erbB/HER receptor-mediated signal transduction. Nat Biotechnol 22:198-203

Lindner JR (2002) Evolving applications for contrast ultrasound. Am J Cardiol 90:72-80

Livet J, Weissman TA, Kang H, Draft RW, Lu J, Bennis RA, Sanes JR, Lichtman JW (2007) Transgenic strategies for combinatorial expression of fluorescent proteins in the nervous system. Nature 450:56-62

Lupold SE, Hicke BJ, Lin Y, Coffey DS (2002) Identification and characterization of nuclease-stabilized RNA molecules that bind human prostate cancer cells via the prostate-specific membrane antigen. Cancer Res 62:4029-4033

Lutz JF, Börner HG, Weichenhan K (2007) 'Click' bioconjugation of a well-defined synthetic polymer and a protein transduction domain. Aust J Chem 60:410-413

Mansfield P, Grannell PK (1973) NMR 'diffraction' in solids? J Phys C Solid State Phys 6:L422-L426

Mason WT (ed) (1999) Fluorescent and luminescent probes for biological activity. Academic Press, London

Massoud TF, Gambhir SS (2003) Molecular imaging in living subjects: seeing fundamental biological processes in a new light. Genes Dev 17:545-580

McCafferty J, Griffiths AD, Winter G, Chiswell DJ (1990) Phage antibodies: filamentous phage displaying antibody variable domains. Nature 348:552-554

Medina C, Santos-Martinez MJ, Radomski A, Corrigan OI, Radomski MW (2007) Nanoparticles: pharmacological and toxicological significance. Br J Pharmacol 150:552-558

Mendez MJ, Green LL, Corvalan JRF, Jia XC, Maynard-Curie CE, Yang XD, Gallo ML, Louie DM, Lee DV, Erickson KL, Luna J, Roy CMN, Abderrahim H, Kirschenbaum F, Noguchi M, Smith DH, Fukushima A, Hales JF, Finer MH, Davis CG, Zsebo KM, Jakobovits A (1997) Functional transplant of megabase human immunoglobulin loci recapitulates human antibody response in mice. Nat Genet 15:146-156

Meresse S, Delbart C, Fruchart JC, Cecchelli R (1989) Low-density lipoprotein receptor on endothelium of brain capillaries. J Neurochem 53:340-345

Metz S, Bonaterra G, Rudelius M, Settles M, Rummeny EJ, DaldrupLink HE (2004) Capacity of human monocytes to phagocytose approved iron oxide MR contrast agents in vitro. Eur Radiol 14:1851-1858

Meyer DL, Schultz J, Lin Y, Henry A, Sanderson J, Jackson JM, Goshorn S, Rees AR, Graves SS (2001) Reduced antibody response to streptavidin through site-directed mutagenesis. Protein Sci 10:491-503

Michaelis K, Hoffmann MM, Dreis S, Herbert E, Alyautdin RN, Michaelis M, Kreuter J, Langer K (2006) Covalent linkage of apolipoprotein $\mathrm{E}$ to albumin nanoparticles strongly enhances drug transport into the brain: J Pharmacol Exp Ther 317:1246-1253

Minshall RD, Sessa WC, Stan RV, Anderson RGW, Malik AB (2003) Caveolin regulation of endothelial function. Am J Physiol Lung Cell Mol Physiol 285:L1179-L1183

Mitra A, Nan A, Papadimitriou JC, Ghandehari H, Line BR (2006) Polymer-peptide conjugates for angiogenesis targeted tumor radiotherapy. Nucl Med Biol 33:43-52

Moghimi SM, Szebeni J (2003) Stealth liposomes and long circulating nanoparticles: critical issues in pharmacokinetics, opsonization and protein-binding properties. Prog Lipid Res 42:463-478

Moghimi SM, Hunter AC, Murray JC (2001) Long-circulating and target-specific nanoparticles: theory to practice. Pharmacol Rev 53:283-318

Morris KN, Jensen KB, Julin CM, Weil M, Gold L (1998) High affinity ligands from in vitro selection: complex targets. Proc Natl Acad Sci USA 95:2902-2907
Morrison SL, Johnson MJ, Herzenberg LA, Oi VT (1984) Chimeric human antibody molecules: mouse antigen-binding domains with human constant region domains. Proc Natl Acad Sci USA 81:6851-6855

Mulder WJM, Strijkers GJ, Habets JW, Bleeker EJW, van der Schaft DWJ, Storm G, Koning GA, Griffioen AW, Nicolay K (2005) MR molecular imaging and fluorescence microscopy for identification of activated tumor endothelium using a bimodal lipidic nanoparticle. FASEB J 19:2008-2010

Mulisch M, Welsch U (Hrsg) (2008) Romeis-mikroskopische technik, 18th edn. Spektrum Akademischer. ISBN: 978-3-8274-1676-6

Nabhan C, Dyer M, Rosen S (2003) Current status of monclonal antibody therapy for chronic lymphocytic leukaemia. Oncology (Huntingt) 17:253-262 discussion 264, 267

Nelson KL, Runge VM (1995) Basic principles of MR contrast. Top Magn Reson Imaging 7:124-136

Niederhauser J (2004) Real-time biomedical optoacoustic imaging. Diss ETH No.15572

Nimpf J, Schneider WJ (2000) From cholesterol transport to signal transduction: low density lipoprotein receptor, very low density lipoprotein receptor and apolipoprotein E receptor-2. Biochim Biophys Acta 1529:287-298

Oberdörster E (2004) Manufactured nanomaterials (fullerenes, C60) induce oxidative stress in the brain of juvenile largemouth bass. Environ Health Perspect 112:1058-1062

Oberdörster G, Maynard A, Donaldson K, Castranova V, Fitzpatrick J, Ausman K, Carter J, Kreyling W, Lai D, Olin S, Monteiro-Riviere N, Warheit D, Yang H (2005a) Principles for characterizing the potential human health effects from exposure to nanomaterials: elements of a screening strategy. Part Fibre Toxicol 2:8

Oberdörster G, Oberdörster E, Oberdörster J (2005b) Nanotoxicology: an emerging discipline evolving from studies of ultrafine particles. Environ Health Perspect 113:823-839

Ohsawa K, Kasamatsu T, Nagashima JI, Hanawa K, Kuwahara M, Ozaki H, Sawai H (2008) Arginine-modified DNA aptamers that show enantioselective recognition of the dicarboxylic acid moiety of glutamic acid. Anal Sci 24:167-172

Osta WA, Chen Y, Mikhitarian K, Mitas M, Salem M, Hannun YA, Cole DJ, Gillanders WE (2004) EpCAM is overexpressed in breast cancer and is a potential target for breast cancer gene therapy. Cancer Res 64:5818-5824

Pagona G, Tagmatarchis N (2006) Carbon nanotubes: materials for medicinal chemistry and biotechnological applications. Curr Med Chem 3:1789-1798

Pan Q, Zhang XL, Wu HY, He PW, Wang F, Zhang MS, Hu JM, Xia B, Wu J (2005) Aptamers that preferentially bind type IVB pili and inhibit human monocytic-cell invasion by Salmonella enterica serovar Typhi. Antimicrob Agents Chemother 49:4052-4060

Partlow KC, Chen J, Brant JA, Neubauer AM, Meyerrose TE, Creer MH, Nolta JA, Caruthers SD, Lanza GM, Wickline SA (2007) 19F magnetic resonance imaging for stem/progenitor cell tracking with multiple unique perfluorocarbon nanobeacons. FASEB J 21:1647-1654

Paschkunova-Martic I, Kremser C, Mistlberger K, Shcherbakova N, Dietrich H, Talasz H, Zou Y, Hugl B, Galanski M, Sölder E, Pfaller K, Höliner I, Buchberger W, Keppler B, Debbage P (2005) Design, synthesis, physical and chemical characterization, and biological interactions of lectin-targeted latex nanoparticles bearing Gd-DTPA chelates: an exploration of magnetic resonance molecular imaging (MRMI). Histochem Cell Biol 123:283-301

Pericleous LM, Richards J, Epenetos AA, Courtenay-Luck N, Deonarain MP (2005) Characterisation and internalisation of recombinant humanised HMFg-1 antibodies against MUC1. Br J Cancer 93:1257-1266

Peters A, Pope CAIII (2002) Cardiopulmonary mortality and air pollution. Lancet 360:1184-1185 
Pitas RE, Boyles JK, Lee SH, Hui D, Weisgraber KH (1987) Lipoproteins and their receptors in the central nervous system. Characterization of the lipoproteins in cerebrospinal fluid and identification of apolipoprotein B,E(LDL) receptors in the brain. J Biol Chem 262:14352-14360

Pomper MG (2005) Translational molecular imaging for cancer. Cancer Imaging 5:S16-S26

Pope CA (2001) Particulate air pollution, C-reactive protein, and cardiac risk. Eur Heart J 22:1149-1150

Posey JA, Saif MW, Carlisle R, Goetz A, Rizzo J, Stevenson S, Rudoltz MS, Kwiatek J, Simmons P, Rowinsky EK, Takimoto CH, Tolcher AW (2005) Phase 1 study of weekly polyethylene glycol-camptothecin in patients with advanced solid tumors and lymphomas. Clin Cancer Res 11:7866-7871

Predescu D, Vogel SM, Malik AB (2004) Functional and morphological studies of protein transcytosis in continuous endothelia. Am J Physiol Lung Cell Mol Physiol 287:L895-L901

Presta LG, Lahr SJ, Shields RL, Porter JP, Gorman CM, Fendly BM, Jardieu PM (1993) Humanization of an antibody directed against IgE. J Immunol 151:2623-2632

Rabin O, Manuel Perez J, Grimm J, Wojtkiewicz G, Weissleder R (2006) An X-ray computed tomography imaging agent based on long-circulating bismuth sulphide nanoparticles. Nat Mater 5:118-122

Reynolds A, Anderson EM, Vermeulen A, Fedorov Y, Robinson K, Leake D, Karpilow J, Marshall WS, Khvorova A (2006) Induction of the interferon response by siRNA is cell type- and duplex length-dependent. RNA 12:988-993

Ribalta J, Vallve JC, Girona J, Masana L (2003) Apolipoprotein and apolipoprotein receptor genes, blood lipids and disease. Curr Opin Clin Nutr Metab Care 6:177-187

Riechmann L, Clark MR, Waldmann H, Winter G (1988) Reshaping human antibodies for therapy. Nature 332:323-327

Rofsky NM, Sherry AD, Lenkinski RE (2008) Nephrogenic systemic fibrosis: a chemical perspective. Radiology 247:608-612

Rossin R, Pan D, Qi K, Turner JL, Sun X, Wooley KL, Welch MJ $(2005){ }^{64} \mathrm{Cu}$-labeled folate-conjugated shell cross-linked nanoparticles for tumor imaging and radiotherapy: synthesis, radiolabeling, and biologic evaluation. J Nucl Med 46:1210-1218

Roth J (1983) The colloidal gold marker system for light and electron microscopy. Theory and application. In: Bullock GR, Petrusz P (eds) Techniques in immunocytochemistry, vol II. Academic Press, London, pp 217-284

Routledge EG, Gorman SD, Clark M (1993) Reshaping antibodies for therapy. In: Clark M (ed) Protein engineering of antibody molecules for prophylactic and therapeutic applications in man. Academic Titles, Nottingham, pp 13-44. ISBN: 1-874695-00-8

Runge VM, Wells JW (1995) Update: safety, new applications, new MR agents. Top Magn Reson Imaging 7:181-195

Salvi SS, Nordenhall C, Blomberg A, Rudell B, Pourazar J, Kelly FJ, Wilson S, Sandström T, Holgate ST, Frew AJ (2000) Acute exposure to diesel exhaust increases IL-8 and GRO-alpha production in healthy human airways. Am J Respir Crit Care Med 161:550557

Satchi-Fainaro R, Puder M, Davies JW, Tran HT, Sampson DA, Greene AK, Corfas G, Folkman J (2004) Targeting angiogenesis with a conjugate of HPMA copolymer and TNP-470. Nat Med 10:255-261

Schiffelers RM, Ansari A, Xu J, Zhou Q, Tang Q, Storm G, Molema G, Lu PY, Scaria PV, Woodle MC (2004) Cancer siRNA therapy by tumor selective delivery with ligand-targeted sterically stabilized nanoparticle. Nucleic Acids Res 32:e149

Schluep T, Cheng JJ, Khin KT, Davis ME (2006a) Pharmacokinetics and biodistribution of the camptothecin-polymer conjugate IT101 in rats and tumor-bearing mice. Cancer Chem Pharmacol $57: 654-662$
Schluep T, Hwang J, Cheng JJ, Heidel JD, Bartlett DW, Hollister B, Davis ME (2006b) Preclinical efficacy of the camptothecin-polymer conjugate IT-101 in multiple cancer models. Clin Cancer Res 12:1606-1614

Schnyder A, Krähenbühl S, Drewe J, Huwyler J (2005) Targeting of daunomycin using biotinylated immunoliposomes: pharmacokinetics, tissue distribution and in vitro pharmacological effects. J Drug Target 13:325-335

Schubert W, Frank PG, Chow CW, Lisanti MP (2001) Caveolae-deficient endothelial cells show defects in the uptake and transport of albumin in vivo. J Biol Chem 276:48619-48622

Schvedova AA, Castranova V, Kisin ER, Schwegler-Berry D, Murray AR, Gandelsman VZ, Maynard A, Baron P (2003) Exposure to carbon nanotube material: assessment of nanotube cytotoxicity using human keratinocyte cells. J Toxicol Environ Health A 66:1909-1926

Scott AM, Lee FT, Jones R, Hopkins W, MacGregor D, Cebon JS, Hannah A, Chong G, U P, Papenfuss A, Rigopoulos A, Sturrock S, Murphy R, Wirth V, Murone C, Smyth FE, Knight S, Welt S, Ritter G, Richards E, Nice EC, Burgess AW, Old LJ (2005) A phase I trial of humanized monoclonal antibody A33 in patients with colorectal carcinoma: biodistribution, pharmacokinetics, and quantitative tumor uptake. Clin Cancer Res 11:4810-4817

Seaton A, Donaldson K (2005) Nanoscience, nanotoxicology, and the need to think small. Lancet 365:923-924

Seibert JA, Boone JM (2005) X-ray imaging physics for nuclear medicine technologists. Part 2: X-ray interactions and image formation. J Nucl Med Technol 33:3-18

Service RF (2004) Nanotoxicology: nanotechnology grows up. Science 304:1732-1734

Shangguan D, Li Y, Tang Z, Cao ZC, Chen HW, Mallikaratchy P, Sefah K, Yang CJ, Tan W (2006) Aptamers evolved from live cells as effective molecular probes for cancer study. Proc Natl Acad Sci USA 103:11838-11843

Shapiro EM, Skrtic S, Koretsky AP (2005) Sizing it up: cellular MRI using micron-sized iron oxide particles. Magn Reson Med 53:329-338

Shellock FG, Kanal E (1999) Safety of magnetic resonance imaging contrast agents. J Magn Reson Imaging 10:477-484

Shiokawa T, Hattori Y, Kawano K, Ohguchi Y, Kawakami H, Toma K, Maitani Y (2005) Effect of polyethyelne glycol linker chain length of folate-linked microemulsions loading Aclacinomycin A on targeting ability and antitumor effect in vitro and in vivo. Clin Cancer Res 11:2018-2025

Shmeeda H, Mak L, Tzemach D, Astrahan P, Tarshish M, Gabizon A (2006) Intracelllular uptake and intracavitary targeting of folateconjugated liposomes in a mouse lymphoma model with upregulated folate receptors. Mol Cancer Ther 5:818-824

Singer JW (2005) Paclitaxel poliglumex (XYOTAX TM, CT-2103): a macromolecular taxane. J Control Release 109:120-126

Sipe JC, Filippi M, Martino G, Furlan R, Rocca MA, Rovaris M, Bergami A, Zyroff J, Scotti G, Comi G (1999) Method for intracellular magnetic labeling of human mononuclear cells using approved iron contrast agents. Magn Reson Imaging 17:1521-1523

Smith KA, Nelson PN, Warren P, Astley SJ, Murray PG, Greenman J (2004) Demystified...recombinant antibodies. J Clin Pathol 57:912-917

Smith J, Kontermann RE, Embleton J, Kumar S (2005) Antibody phage display technologies with special reference to angiogenesis. FASEB J 19:331-341

Steerenberg PA, Zonnenberg JA, Dormans JA, Joon PN, Wouters IM, van Bree L, Scheepers PTJ, van Loveren H (1998) Diesel exhaust particles induced release of interleukin 6 and 8 by (primed) human bronchial epithelial cells (BEAS 2B) in vitro. Exp Lung Res $24: 85-100$ 
Stern M, Herrmann R (2005) Overview of monoclonal antibodies in cancer therapy: present and promise. Crit Rev Oncol Hematol 54:11-29

Stockwin LH, Holmes S (2003) The role of therapeutic antibodies in drug discovery. Biochem Soc Trans 31:433-436

Svenson S, Tomalia DA (2005) Dendrimers in biomedical applications: reflections on the field. Adv Drug Deliv Rev 57:2106-2129

Szellas T, Hoppe M (2007) Breaking the barriers in bio research. Imaging Microsc 9:26-27

Tanenbaum LN (2006) Clinical 3T MR imaging: mastering the challenges. Magn Reson Imaging Clin North Am 14:1-15

Teply BA, Rocha FG, Levy-Nissenbaum E, Langer R, Farokhzad OC (2006) Nanoparticle-aptamer bioconjugates for targeted antineoplastic drug delivery. Am J Drug Deliv 4:123-130

Ter-Pogossian MM (1985) PET, SPECT, and NMRT: competing or complementary disciplines? J Nucl Med 26:1487-1498

Thistlethwaite JR Jr, Cosimi AB, Delmonico FL, Rubin RH, TalkoffRubin N, Nelson PW, Fang L, Russell PS (1984) Evolving use of OKT3 monoclonal antibody for treatment of renal allogrft rejection. Transplantation 38:695-700

Thomas R, True LD, Bassuk JA, Lange PH, Vessella RL (2000) Differential expression of osteonectin/SPARC during human prostate cancer progression. Clin Cancer Res 6:1140-1149

Tian H (2002) Combinatorial selection of RNA ligands for complex cellular targets: the RNA ligands-based proteomics. Mol Cell Proteomics 1:99-103

Tiruppathi C, Song W, Bergenfeldt M, Sass P, Malik AB (1997) Gp60 activation mediates albumin transcytosis in endothelial cells by tyrosine kinase-dependent pathway. J Biol Chem 272:2596825975

Tuerk C, Gold L (1990) Systematic evolution of ligands by exponential enrichment: RNA ligands to bacteriophage T4 DNA polymerase. Science 249:505-510

Tuma PL, Hubbard AL (2003) Transcytosis: crossing cellular barriers. Physiol Rev 83:871-932

Ulrich H, Magdesian MH, Alves MJM, Colli W (2002) In vitro selection of RNA aptamers that bind to cell adhesion receptors of Trypanosoma cruzi and inhibit cell invasion. J Biol Chem 277:20756-20762

van Loghem E (1986) Allotypic markers. Monogr Allergy 19:40-51

Vasey PA, Kaye SB, Morrison R, Twelves C, Wilson P, Duncan R, Thomson AH, Murray LS, Hilditch TE, Murray T, Burtles S, Fraier D, Frigerio E, Cassidy J (1999) Phase I clinical and pharmacokinetic study of PK1 N-(2-hydroxypropyl)methacrylamide copolymer doxorubicin: first member of a new class of chemotherapeutic agents-drug-polymer conjugates. Clin Cancer Res 5:83-94

Vasile E, Simionescu M, Simionescu N (1983) Visualization of the binding, endocytosis and transcytosis of low-density lipoprotein in the arterial endothelium in situ. J Cell Biol 96:1677-1689

Vaughn TJ, Williams AJ, Pritchard K, Osbourn JK, Pope AR, Earnshaw JC, McCafferty J, Hodits RA, Wilton J, Johnson KS (1996) Human antibodies with sub-nanomolar affinities isolated from a large non-immunized phage display library. Nat Biotechnol 14:309-314

Vicent MJ (2007) Polymer-drug conjugates as modulators of cellular apoptosis. AAPS J 9:E200-E207

Vitaliti A, Wittmer R, Steiner R, Wyder L, Neri D, Klemenz R (2000) Inhibition of tumor angiogenesis by a single chain antibody directed against vascular endothelial growth factor. Cancer Res 60:4311-4314

Vogel SM, Minshall RD, Pilipovic M, Tiruppathi C, Malik AB (2001) Albumin update and transcytosis in endothelial cells in vivo induced by albumin-binding protein. Am J Physiol Lung Cell Mol Physiol 281:L1512-L1522
Vogel V, Langer K, Balthasar S, Schuck P, Mächtle W, Haase W, van den Broek JA, Tziatzios C, Schubert D (2002) Characterization of serum albumin nanoparticles by sedimentation velocity analysis and electron microscopy. Progr Colloid Polym Sci 119:31-36

Waldmann TA (2003) Immunotherapy: past, present and future. Nat Med 9:269-277

Wang YX, Hussain SM, Krestin GP (2001) Superparamagnetic iron oxide contrast agents: physicochemical characteristics and applications in MR imaging. Eur Radiol 11:2319-2331

Wang XD, Pang YJ, Ku G, Xie XY, Stoica G, Wang LV (2003) Noninvasive laser-induced photoacoustic tomography for structural and functional in vivo imaging of the brain. Nat Biotechnol $21: 803-806$

Wang X, Xie X, Ku G, Stoica G, Wang LV (2006) Non-invasive imaging of hemoglobin concentration and oxygenation in the rat brain using high-resolution photoacoustic tomography. J Biomed Opt $11: 1-9$

Wang AZ, Bagalkot V, Gu F, Alexis F, Vasilliou C, Cima M, Jon S, Farokhzad O (2007) Novel targeted aptamer-superparamagnetic iron oxide nanoparticle bioconjugates for combined prostate cancer imaging and therapy. Int J Rad Oncol Biol Phys 69(Suppl 1):S110-S111

Wartlick H, Michaelis K, Balthasar S, Strebhardt K, Kreuter J, Langer K (2004) Highly specific HER2-mediated cellular uptake of antibody-modified nanoparticles in tumour cells. J Drug Target 12:461-471

Watkins G, Douglas-Jones A, Bryce R, Mansel RE, Jiang WG (2005) Increased levels of SPARC (osteonectin) in human breast cancer tissues and its association with clinical outcomes. Prostaglandins Leukot Essent Fatty Acids 72:267-272

Weisgraber KH (1994) Apolipoprotein E: structure-function relationships. Adv Protein Chem 45:249-302

Weissleder R, Mahmood U (2001) Molecular imaging. Radiology 219:316-333

Weissleder R, Pittet MJ (2008) Imaging in the era of molecular oncology. Nature 452:580-589

Weissleder R, Elizondo G, Wittenberg J, Rabito CA, Bengele HH, Josephson L (1990) Ultrasmall superparamagnetic iron oxide: characterization of a new class of contrast agents for MR imaging. Radiology 175:489-493

Wickline SA, Lanza GM (2003) Nanotechnology for molecular imaging and targeted therapy. Circulation 107:1092-1095

Wieser E, Strohmeyer D, Rogatsch H, Horninger W, Bartsch G, Debbage $P$ (2004) Access of tumor-derived macromolecules and cells to the blood: an electron microscopical study of structural barriers in microvessel clusters in highly malignant primary prostate carcinomas. Prostate 62:123-132

Willis MC, Collins BD, Zhang T, Green LS, Sebesta DP, Bell C, Kel$\operatorname{logg}$ E, Gill SC, Magallanez A, Knauer S, Bendele RA, Gill PS, Janjić N (1998) Liposome-anchored vascular endothelial growth factor aptamers. Bioconjug Chem 9:573-582

Winter G, Griffiths AD, Hawkins RE, Hoogenboom HR (1994) Making antibodies by phage display technology. Annu Rev Immunol 12:433-455

Woods M, Woessner DE, Sherry AD (2006) Paramagnetic lanthanide complexes as PARACEST agents for medical imaging. Chem Soc Rev 35:500-511

Wu X, Liu H, Liu J, Haley KN, Treadway JA, Larson JP, Ge N, Peale F, Bruchez MP (2003) Immunofluorescent labeling of cancer marker Her2 and other cellular targets with semiconductor quantum dots. Nat Biotechnol 21:41-46

Wu YL, Ye Q, Foley LM, Hitchens TK, Sato K, Williams JB, Ho C (2006) In situ labeling of immune cells with iron oxide particles: an approach to detect organ rejection by cellular MRI. Proc Natl Acad Sci USA 103:1852-1857 
Xie YL, Lu W, Jiang XG (2006) Improvement of cationic albumin conjugated pegylated nanoparticles holding NC-1900, a vasopressin fragment analog, in memory deficits induced by scopolamine in mice. Behav Brain Res 173:76-84

Xing Y, Chaudry Q, Shen C, Kong KY, Zhau HE, Chung LW, Petros JA, O'Regan RM, Yezhelyev MV, Simons JW, Wang MD, Nie S (2007) Bioconjugated quantum dots for multiplexed and quantitative immunohistochemistry. Nat Protoc 2:1152-1165

Xu M, Wang LV (2006) Biomedical photoacoustics. Rev Sci Instrum 77:04110101-22

Xu L, Huang CC, Huang W, Tang WH, Rait A, Yin YZ, Cruz I, Xiang LM, Pirollo KF, Chang EH (2002) Systemic tumor-targeted gene delivery by anti-transferrin receptor scFv immunoliposomes. Mol Cancer Ther 1:337-346

Yamashita T, Budhu A, Forgues M, Wang XW (2007) Activation of hepatic stem cell marker EpCAM by Wnt $\{$ beta $\}$-catenin signaling in hepatocellular carcinoma. Cancer Res 67:10831-10839

Yamawaki H, Iwai N (2006) Mechanisms underlying nano-sized airpollution-mediated progression of atherosclerosis: carbon black causes cytotoxic injury/inflammation and inhibits cell growth in vascular endothelial cells. Circ J 70:129-140

Yang HM, Ma JY, Castranova V, Ma JK (1997) Effects of diesel exhaust particles on the release of interleukin-1 and tumor necrosis factor-alpha from rat alveolar macrophages. Exp Lung Res 23:269-284

Yumoto R, Nishikawa H, Okamoto M, Katayama H, Nagai J, Takano M (2006) Clathrin-mediated endocytosis of FITC-albumin in alveolar type II epithelial cell line RLE-6TN. Am J Physiol Lung Cell Mol Physiol 290:L946-L955
Zabow G, Dodd S, Moreland J, Koretsky A (2008) Micro-engineered local field control for high-sensitivity multispectral MRI. Nature 453:1058-1063

Zamboni WC, Goel S, Iqbal T, Parise RA, Sandra Strychor S, Repinski TVW, Egorin MJ, Mani S (2006) Clinical and pharmacokinetic study evaluating the effect of food on the disposition of 9-nitrocamptothecin and its 9-aminocamptothecin metabolite in patients with solid tumors. Cancer Chem Pharmacol 57:631-639

Zelivyanskaya ML, Nelson JA, Poluektova L, Uberti M, Mellon M, Gendelman HE, Boska MD (2003) Tracking superparamagnetic iron oxide labeled monocytes in brain by high-field magnetic resonance imaging. J Neurosci Res 73:284-295

Zhang Y, Pardridge WM (2001) Conjugation of brain-derived neurotrophic factor to a blood-brain barrier drug targeting system enables neuroprotection in regional brain ischemia following intravenous injection of the neurotrophin. Brain Res 889:49-56

Zhang Y, Zhu C, Pardridge WM (2002) Antisense gene therapy of brain cancer with an artificial virus gene delivery system. Mol Ther 6:67-72

Zhang K, Maslov G, Stoica G, Wang LV (2006) Functional photoacoustic microscopy for high-resolution and noninvasive in vivo imaging. Nat Biotechnol 24:848-851

Zhang L, Radovic-Moreno AF, Alexis F, Gu FX, Basto PA, Bagalkot V, Jon S, Langer RS, Farokhzad OC (2007) Co-delivery of hydrophobic and hydrophilic drugs from nanoparticle-aptamer bioconjugates. ChemMedChem 2:1268-1271

Zhang S, Zhu X, Chen Z, Cai C, Lin T, Zhong J (2008) Improvement in the contrast of CEST MRI via intermolecular double quantum coherences. Phys Med Biol 53:N287-N296 